\title{
Distribution of living larval Chironomidae (Insecta: Diptera) along a depth transect at Kigoma Bay, Lake Tanganyika: implications for palaeoenvironmental reconstruction
}

\author{
H. Eggermont ${ }^{1 *}$, D. Kennedy ${ }^{2}$, S.T. Hasiotis ${ }^{3}$, D. Verschuren ${ }^{1} \&$ A. Cohen ${ }^{2}$ \\ ${ }^{1}$ Limnology Unit, Ghent University, K.L. Ledeganckstraat 35, B-9000 Ghent, Belgium \\ ${ }^{2}$ Department of Geoscience, University of Arizona, Tuscon, Arizona, 85721, U.S.A. \\ ${ }^{3}$ Department of Geology and the Natural History Museum and Biodiversity Research Center, \\ University of Kansas, Lawrence, Kansas, 66045, U.S.A.
}

\begin{abstract}
We analysed the distribution of living larval Chironomidae (Insecta: Diptera) along a depth transect (0-80 m water depth) at Kigoma Bay in Lake Tanganyika (East Africa) to explore the ecological indicator value of Lake Tanganyika's midge fauna and to delineate the habitat preferences of resident larvae. Additionally, by comparing the taxonomic resolution reached in live versus fossil chironomid studies in this lake, we appraised the general information content of African fossil chironomid assemblages and, therefore, the quality of African chironomid-based palaeoenvironmental reconstructions. We found 141 chironomid specimens, representing two Tanypodinae, one Orthocladinae and 13 Chironominae (seven Chironomini and six Tanytarsini) taxa. All of these are conspecific to larval types encountered in subfossil collections from Lake Tanganyika or smaller East African lakes, but their differential diagnoses are updated here to include exoskeletal elements that are generally better preserved on live specimens. The chironomid assemblage collected in the Kigoma Bay depth samples is dominated by a few species of chironomine detritus and algae feeders, concentrated in areas of high macrophyte density. Additionally, there is a small component of tanypodine predatory taxa, along with several relatively rare, possibly habitat-specialist, taxa of both subfamilies. Our results further indicate that littoral and sublittoral palaeoenvironments in Lake Tanganyika may generally be inferred from high fossil density and diversity. The fairly high correspondence between inferred habitat preference of fossil and live collections in Lake Tanganyika indicates that, in large African lakes, the near-to-offshore gradient in chironomid habitat is imprinted on fossil assemblages. Hence, death assemblages deposited recently at various locations and microhabitats within Lake Tanganyika can be used as modern calibration data for palaeodepth inference. Moreover, Tanganyikan fossil-based taxonomy fully matches the taxonomic resolution reached in this study, so ecological information retrieved from live specimens can immediately be used for palaeoenvironmental studies.
\end{abstract}

Key words: Chironomidae, depth gradient, fossils, Lake Tanganyika, living fauna, morphotypes, palaeoecology, taxonomy.

\section{INTRODUCTION}

This paper describes the distribution of living chironomid larvae (Insecta: Diptera) along a depth transect at Kigoma Bay, Lake Tanganyika. This lake, located in the western branch of the East African Rift, is one of the world's largest and oldest freshwater lakes (c. 9-12 My; Cohen et al. 1993b). It harbors over 1500 species of protists, plant and animals, including mostly endemic species flocks of cichlid and non-cichlid fishes, mollusks and crustaceans (Coulter, 1991). This high biodiversity is due, in part, to the lake's great antiquity, and ecological complexity, with a wide variety of

*To whom correspondence should be addressed.

E-mail: hilde.eggermont@ugent.be littoral, sublittoral, and profundal habitats. More specifically, the tectonic activity which has shaped this basin produces a shoreline mosaic of rocky slopes and prograding sandy platforms, resulting in a variety of benthic environments ranging from mud, silt, and sand lakebeds to shell lags, boulder fields, and stromatolites (Park et al. 2000). The aquatic environment of Lake Tanganyika is further characterized by its combination of warm temperatures $\left(25-28{ }^{\circ} \mathrm{C}\right.$ at the surface, $24^{\circ} \mathrm{C}$ at depth; Plisnier et al. 1999), a deep oxygenated water column (80-100 m in the north basin; Degens et al. 1971) and strong wave action on steeply sloping, rocky or sandy shores (Cohen et al. 1993a). Together, 
these physical factors produce an extraordinary level of habitat heterogeneity that, coupled with the lake's age, has allowed a high degree of speciation through niche differentiation, as is the case in highly specialized species flocks of cichlid fish (Hori et al. 1993). For generalist organisms with modest levels of habitat differentiations such as ostracods, environmental heterogeneity can promote diversity through metapopulation dynamics characterized by frequent local extinction and subsequent recolonization of local sites, with relatively little change in overall species richness (Cohen 1995, 2000). In either case, the lake's great depth and deep, well-oxygenated water column allow the varied habitats to move up and down its steeply sloped sides with water level during periods of climate change ( $c f$. Nicholson 1999; Alin \& Cohen 2003), creating a temporally persistent environment favourable to maintaining rich species assemblages (Cohen et al. 1993a).

Chironomids are a family of true flies (Insecta: Diptera) of which the larvae constitute one of the most abundant bottom-dwelling macroinvertebrates in continental aquatic ecosystems (Cranston 1995). They inhabit the uppermost sediments of both littoral and profundal (deep-water) environments, cling to or burrow into aquatic plants, tunnel in moist wood, or parasitize other invertebrates (Oliver \& Roussel 1983). Studies of Lake Tanganyika's chironomid larvae are very few. Theunissen (1993) assessed the influence of pollution on the species composition and morphological deformities of chironomid larvae inhabiting the Ntahangwa River (10 sample sites, between the mouth of the river and $22.5 \mathrm{~km}$ upstream) and Bujumbura Bay in the northern part of the lake (15 sample sites at 5-m depth intervals between 0 and $64 \mathrm{~m}$ ), and included fragmentary taxonomic notes on the recovered morphotypes. Eggermont \& Verschuren (2003c) analysed the species diversity and distribution of recently buried chironomid remains in bottom environments along the Burundi and Tanzania coastline of Lake Tanganyika adjacent to pristine and deforested drainages (36 surface sediment samples between 53 and $189 \mathrm{~m}$ water depth), in order to investigate the ecological impact of sediment pollution caused by anthropogenic soil erosion; two companion papers (Eggermont \& Verschuren 2003a,b) provided a taxonomic inventory of this subfossil chironomid collection.

Palaeolimnologists have increasingly used fossil remains of chironomid larvae preserved in lake sediments to reconstruct, both quantitatively and qualitatively, long-term environmental change affecting lakes and adjacent landscapes because they have proven useful as biological indicators in contemporary water-quality monitoring of lakes and rivers (Brinkhurst 1974; Rosenberg \& Resh 1993). Particularly in north-temperate Europe and North America, statistically robust inference models have been developed for quantitative reconstruction of past changes in temperature, salinity, lake trophic status and oxygen regime (see Walker 2001, 2007). The development of chironomid palaeoecology as a quantitative research discipline in tropical regions such as Africa has been significantly slower, mostly due to incomplete taxonomic knowledge of tropical chironomid larvae, and scarce information on the ecology of individual species that is essential to make them useful as bioindicators (Verschuren \& Eggermont 2006). Over the past decade, however, progress in the identification of subfossil remains of chironomid larvae preserved in African lake sediments (Verschuren 1997; Eggermont \& Verschuren 2003a,b, 2004a,b; Eggermont et al. 2005; Eggermont \& Verschuren 2007) has allowed a wider use of fossil midges as bioindicators in African palaeoenvironmental research, including the development of chironomid-based inference models (so-called transfer functions) for quantitative reconstruction of past salinity changes in East African lakes (Verschuren et al. 2004; Eggermont et al. 2006). Standard approaches to developing transfer functions are based on training sets consisting of modern, surface-sediment assemblages from many lakes encompassing the environmental gradient of interest. In equatorial East Africa (Kenya, Uganda and Tanzania) the currently available training set is based on 65 fossil chironomid morphotypes recovered from surface sediments of 67 lakes, spanning a salinity gradient between 34 and $68000 \mu \mathrm{S} / \mathrm{cm}$. These inference models, however, are not applicable in Lake Tanganyika because the species overlap between this lake and other East African lakes is too limited (26 taxa, or $\sim 34 \%$ of known Lake Tanganyika taxa) to allow ecological specificity of East African taxa to be transferred to Lake Tanganyika (cf. Rosenberg \& Resh 1993). The reason for this is that Lake Tanganyika, being a large lake with wave-swept rocky and sandy shores, differs environmentally from smaller East African lakes on which our available training set is based. An alternative 


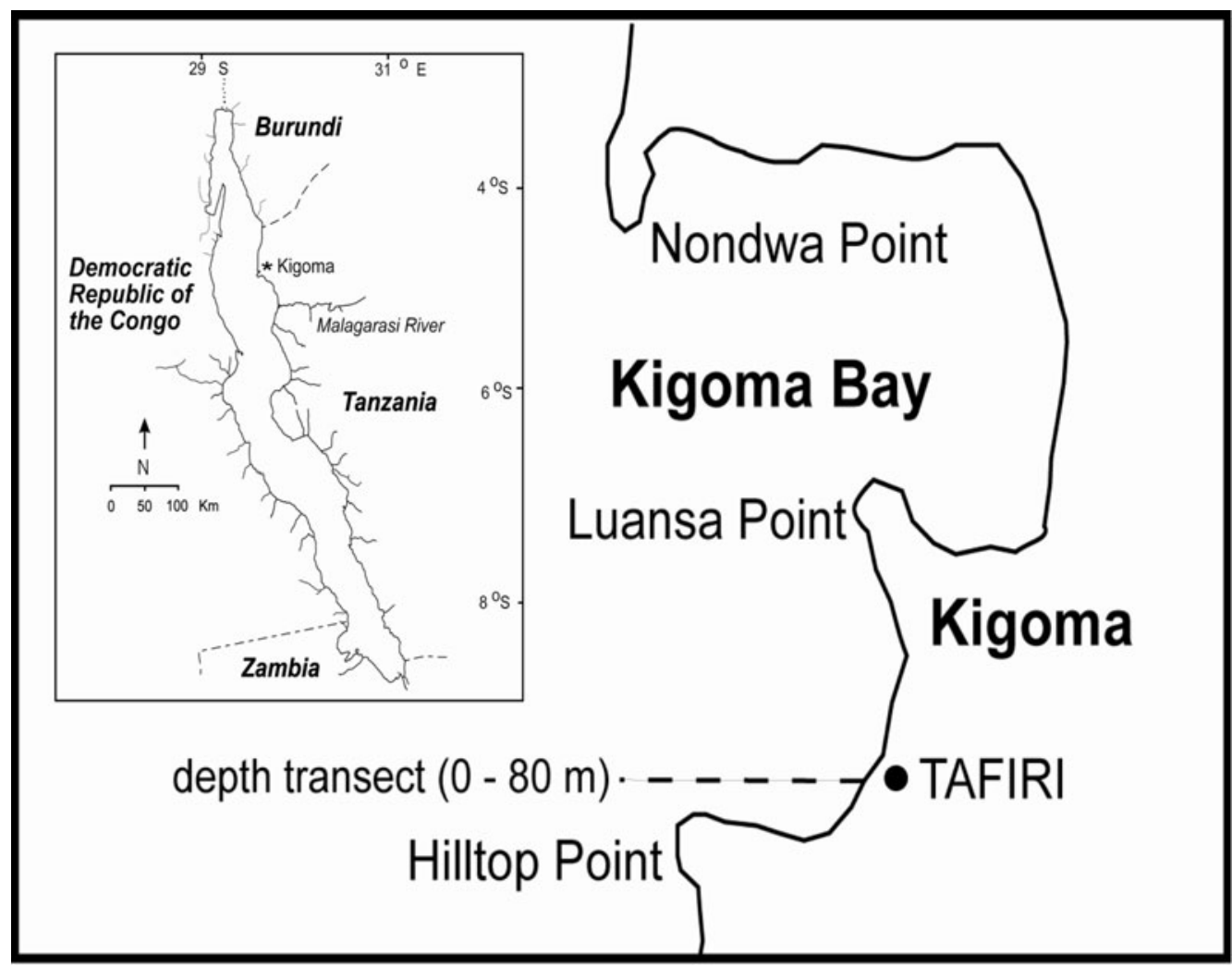

Fig. 1. Location map of the Kigoma Bay depth transect in Lake Tanganyika. Inset shows the entire Lake Tanganyika basin, along with bordering East African countries.

approach for Lake Tanganyika, and possibly other large African Rift lakes, would be the development of a within-lake depth inference model, exploiting internal lake gradients rather than gradients among lakes. Lake Tanganyika lends itself well for this purpose given that the lake is exceptionally large and spans substantial gradients in bottom sediment and oxygen.

The first step towards the development of fossil-based, within-lake depth inference models is to delineate habitat preferences of resident larvae. Here we describe the living chironomid distribution along a depth gradient in Kigoma Bay, and compare our results with the two previous chironomid studies conducted in the lake. Additionally, by comparing the taxonomic resolution reached in the live and fossil chironomid studies in this lake, we appraise the general information content of African fossil chironomid assemblages and, thus, the quality of African chironomid-based palaeoenvironmental reconstructions. Collectively, these data are integral to establish Lake Tanga- nyika's chironomid fauna as indicators for past environmental conditions.

\section{MATERIAL AND METHODS}

\section{Study sites and field methods}

Lake Tanganyika (surface area $32600 \mathrm{~km}^{2}$, drainage area $220000 \mathrm{~km}^{2}$ ) is the deepest (max. $1470 \mathrm{~m}$, mean $580 \mathrm{~m}$ ) and by volume the largest $(19690 \mathrm{~km}$, McGlue et al. 2008) freshwater lake in East Africa. Its water column is permanently stratified, so that habitable bottom environments are restricted to a narrow nearshore fringe of steeply sloping lake bottom above the oxycline, situated at $\sim 100 \mathrm{~m}$ water depth in the northern half of the lake. Samples were collected in July 2004 along a depth transect extending from the splash zone to $80 \mathrm{~m}$ water depth immediately adjacent to the Tanzanian Fisheries Research Institute's (TAFIRI) Kigoma Field Station, located between Luansa Point and Hilltop Point (Fig. 1). This depth transect was characterized by varying wave energy over a 


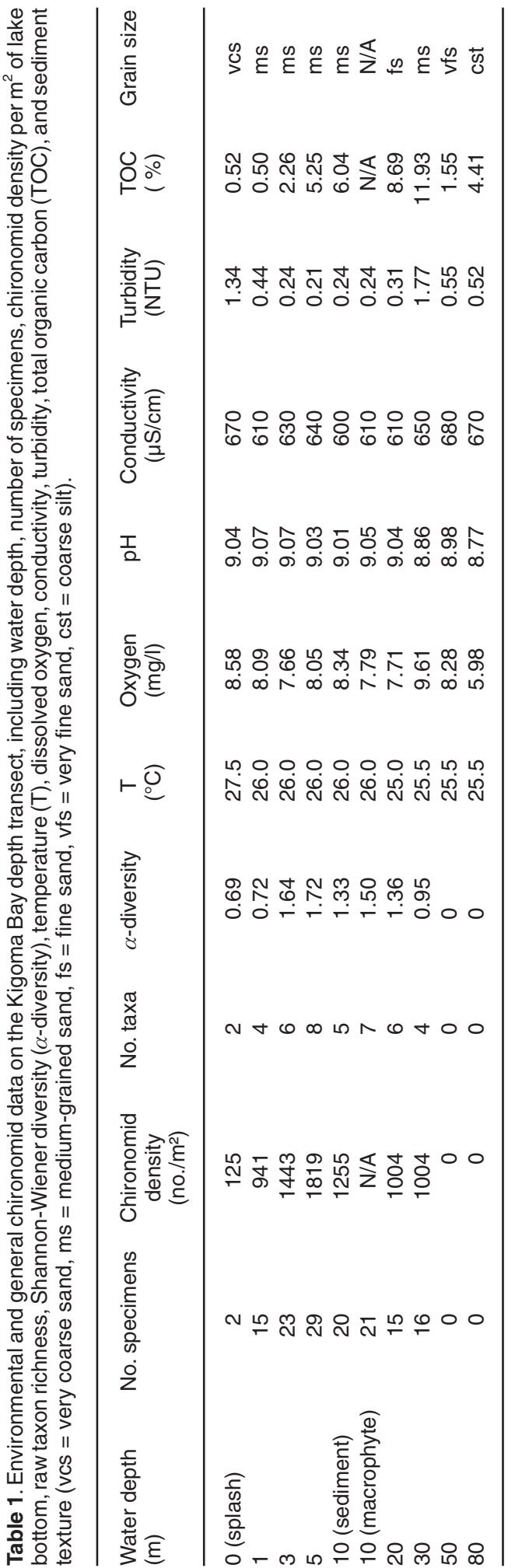

mostly sandy lake bottom down to $30 \mathrm{~m}$ depth, with finer sediments underlying deeper water (Table 1; Fig. 2). Submerged macrophytes, including Hydrilla verticillata and Potamogeton spp., were restricted to a narrow band between two and $10 \mathrm{~m}$ water depth.

A fixed volume of $271 \mathrm{~cm}$ of sediment was collected from the splash zone and at depths of $1,3,5,10,20$ and $30 \mathrm{~m}$, using a plastic petri dish and a flat fiberglass sheet. With the exception of the splash zone, these samples were gathered by SCUBA diving, and sealed in plastic zipper lock bags in situ. Care was taken not to disturb the bottom sediment during collection, in order to ensure that any organisms at or near the surface were collected along with the sediment. In addition, a qualitative sample of branches from a submerged macrophyte, Hydrilla verticillata, was taken at $10 \mathrm{~m}$ water depth, and sealed in a plastic bag. Samples at 50 and $80 \mathrm{~m}$ water depth were collected using a Ponar grab sampler (i.e. $3540 \mathrm{~cm}$ of sediment per sample). Temperature, $\mathrm{pH}$, oxygen, conductivity and turbidity were measured at each sample site using a YSI 6500 multimeter.

\section{Laboratory analyses}

Sediments were classified by grain size according to the Udden-Wentworth scale (Wentworth 1922). Total organic carbon (TOC) of the sediments was quantified by Loss on Ignition following Heiriet al. (2001). Samples were rinsed through a $250 \mu \mathrm{m}$ sieve, and larvae were preserved in $80 \%$ ethanol until analysis. Head capsules were severed from the body, and both parts were cleared by heating them in $10 \% \mathrm{KOH}$ for several minutes (Oliver \& Roussel 1983). After clearing, head capsules and larval bodies were rinsed with distilled water, dehydrated in an ethanol series, and mounted in glycerine on microscope slides; coverslips were sealed with a synthetic epoxy. Identification was done with a compound microscope at $\times 100-400$ magnification, by comparison with reference collections from Lake Tanganyika (Eggermont \& Verschuren 2003a,b) and 73 low- and mid-elevation lakes in East Africa (Verschuren 1997; Eggermont \& Verschuren 2004a,b); descriptions and illustrations in Chrispeels (1959), McLachlan (1969), Lehmann (1979, 1981), Epler (1988) and Harrison (1993, 1996); all relevant taxonomic literature on African Chironomidae (see Eggermont \& Verschuren 2003a); and general references on Holarctic Chironomidae (Wiederholm 1983; 
Moller-Pillot 1984a,b; Epler 1995, 2001; Brooks et al. 2007).

In the fully revised diagnoses presented here, skeletal elements are described in order of their preservation potential in fossil specimens: (1) mentum; (2) ventromental plates; (3) mandibles; (4) other mouth parts as premandibles and pecten epipharyngis; and (5) antennae and other components of the head capsule. Wherever possible such body features as anterior and posterior parapods were used to answer questions of taxonomic identity. Morphological terminology follows Sæther (1980) and Brooks et al. (2007). Morphological differentiation of specimens and name designations follows criteria set out by Eggermont \& Verschuren (2003a), making use of both morphological and biogeographical considerations. Representative specimens were photographed with a Nikon Coolpix 990 digital camera, and presented here as Adobe Photoshop collages of stacked partial images, each with certain skeletal elements in focus. Species richness was evaluated using the raw number of taxa present; species diversity was calculated using the ShannonWiener diversity index (Shannon \& Wiener 1963) in Primer ${ }^{\circledR}$ version 5.2.4 (Primer-E Ltd 2001).

\section{RESULTS}

\section{Differential diagnoses and presumed ecology}

Analysis of the nine sediment samples and one plant sample yielded 141 chironomid specimens, representing 2 Tanypodinae, 1 Orthocladinae and 13 Chironominae (7 Chironomini and 6 Tanytarsini) taxa (Fig. 2). All of these are conspecific to larval types encountered in fossil collections from Lake Tanganyika (Eggermont \& Verschuren 2003a,b) or from smaller East African lakes (Verschuren 1997; Eggermont \& Verschuren 2004a,b). Judging from comparison with morphological diversity within and between genera in the better-known Holarctic fauna, most larval morphotype taxa must be equivalent to biological species, or groups of closely related species. Taxon diagnoses are here revised to now include descriptions of diagnostic features better, though not exclusively, preserved in live specimens. To avoid redundancy with previous work, differential diagnoses are not repeated (i.e. only the new elements are mentioned herein) and we refer to figures in Eggermont \& Verschuren $(2003 a, b, 2004 a, b)$ for additional illustrations. All taxa are provided with a note on their taxonomy, depth distribution as derived from this study, and presumed ecology according to the literature. Genera are listed in alphabetical order within each of the subfamilies and tribes, following Freeman \& Cranston (1983) and Harrison (2000).

\section{Subfamily Tanypodinae Tribe Macropelopini}

\section{Procladius near brevipetiolatus (Goetghebuer)}

\section{$(n=17)$, Fig. 3}

This larval type was previously described on the basis of fossil specimens from Lake Tanganyika ( $n=192$; figs 3-4 in Eggermont \& Verschuren 2003a). The revised diagnosis now also includes the antenna, cephalic setation, and body parts: Antenna with four tubular segments; length of first segment $\sim 4$ times its basal width, ring organ at about a third from the distal end; length of second segment $\sim 4$ times its basal width, greater than twice the length of the remaining two segments, which are both small and inconspicuous; blade seated distally on the basal segment and about as long as the flagellum; style and Lauterborn organs seated distally on the second segment. Cephalic setation keys out to group A3 of Rieradevall \& Brooks (2001) with ventral pore (VP) and submental seta ( $\left.\mathrm{SS}_{\mathrm{m}}\right)$ located between seta 9 (S9) and seta 10 (S10), VP nearly lateral to S10; on the dorsal side, dorsal pore (DP) present, seta 8 (S8) and seta 7 (S7) in an angulate line, and seta 5 (S5) anteromesial to S8. Anterior parapods with numerous short, median, and long claws with many minute points on the inner edge; posterior parapods with at least nine long claws and four smaller, sickle-shaped claws all being simple.

There are seven known Procladius species in sub-Saharan Africa (Freeman \& Cranston 1980), of which at least $P$. brevipetiolatus (Goetghebuer) and P. albitalus Freeman are widely distributed in East Africa. Thus far, only the larva of P. brevipetiolatus has been described, based on live specimens (Harrison 1991), based on fossil specimens (Verschuren 1997; Eggermont \& Verschuren 2004a). The present larval type closely resembles the latter in all aspects, including the antennal complex described earlier but differs from it by having a dorsomentum with almost always less than seven teeth on either side of the median, even in third and fourth instar larvae. Moreover, the posterior parapods seem to lack the many points 


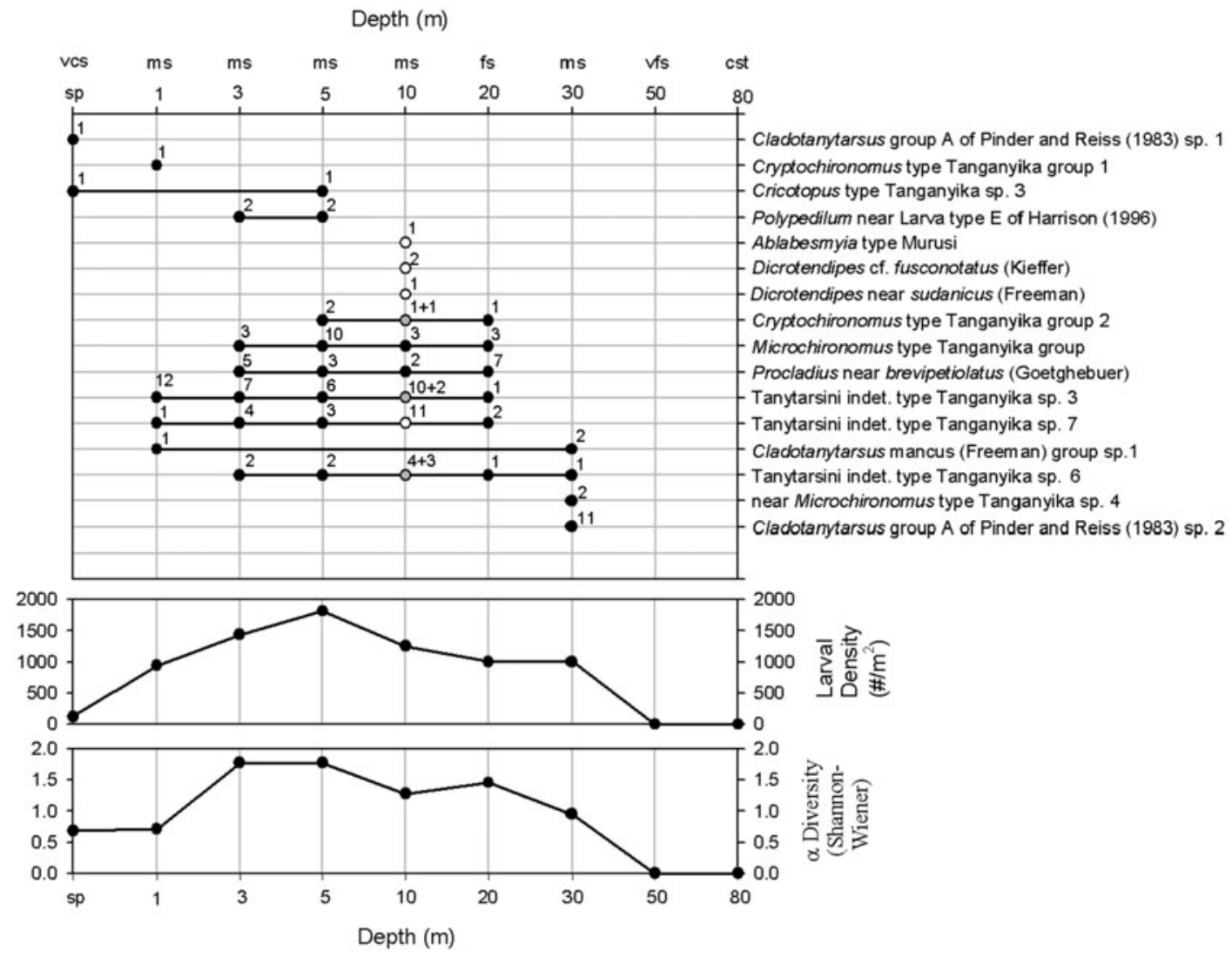

Fig. 2. Distribution of larval Chironomidae along a depth transect of 0-80 m in Kigoma Bay, Lake Tanganyika, East Africa. The top graph depicts individual morphotype presence in lake bottom samples at the corresponding depths (black dots). At $10 \mathrm{~m}$, the white dots indicate morphotypes recorded from a macrophyte sample at this depth, with grey dots showing morphotypes found on both the macrophyte and in the $10 \mathrm{~m}$ sediment sample. The middle and lower graphs show larval density and alpha diversity vs depth, respectively. Sediment texture (vcs = very coarse sand, $\mathrm{ms}=$ medium sand, fs = fine sand, vfs = very fine sand, cst = coarse silt); number of specimens per sample are also indicated.

on the inner edge that are described for real P. brevipetiolatus (see Harrison 1991). In contrast to $P$. brevipetiolatus, it has never been found in fossil material from smaller East African lakes (Eggermont \& Verschuren 2004b).

Procladius larvae are known as predator-engulfers of Protozoa, microcrustaceans, and aquatic insects (Coffman \& Ferrington 1996). In Africa, P. brevipetiolatus is reported from a variety of vegetated and unvegetated sediments, mud and sand (Verschuren, 1997). In Lake Tanganyika, fossil P. near brevipetiolatus did not display a significant relationship with any of the environmental gradients in bottom habitat, but their fossil distribution did show some preference for shallow-water sediments rich in coarse plant debris and sand
(Eggermont \& Verschuren, 2003c). Theunissen (1993) found live Procladius between the splash zone and $64 \mathrm{~m}$ water depth, but most abundantly at 30-35 m water depth. We found the present morphotype on fine- and medium-grained sand substrates between 3 and $20 \mathrm{~m}$, often associated with weed beds (Fig. 2).

\section{Tribe Pentaneurini}

Ablabesmyia type Murusi $(n=1)$, Fig. 4

This larval type was previously described on the basis of fossil specimens from small and mediumsized crater lakes ( $n=154$; figs 11-13 in Eggermont \& Verschuren 2004a). The revised diagnosis now includes body parts: slender anal tubules; anterior 


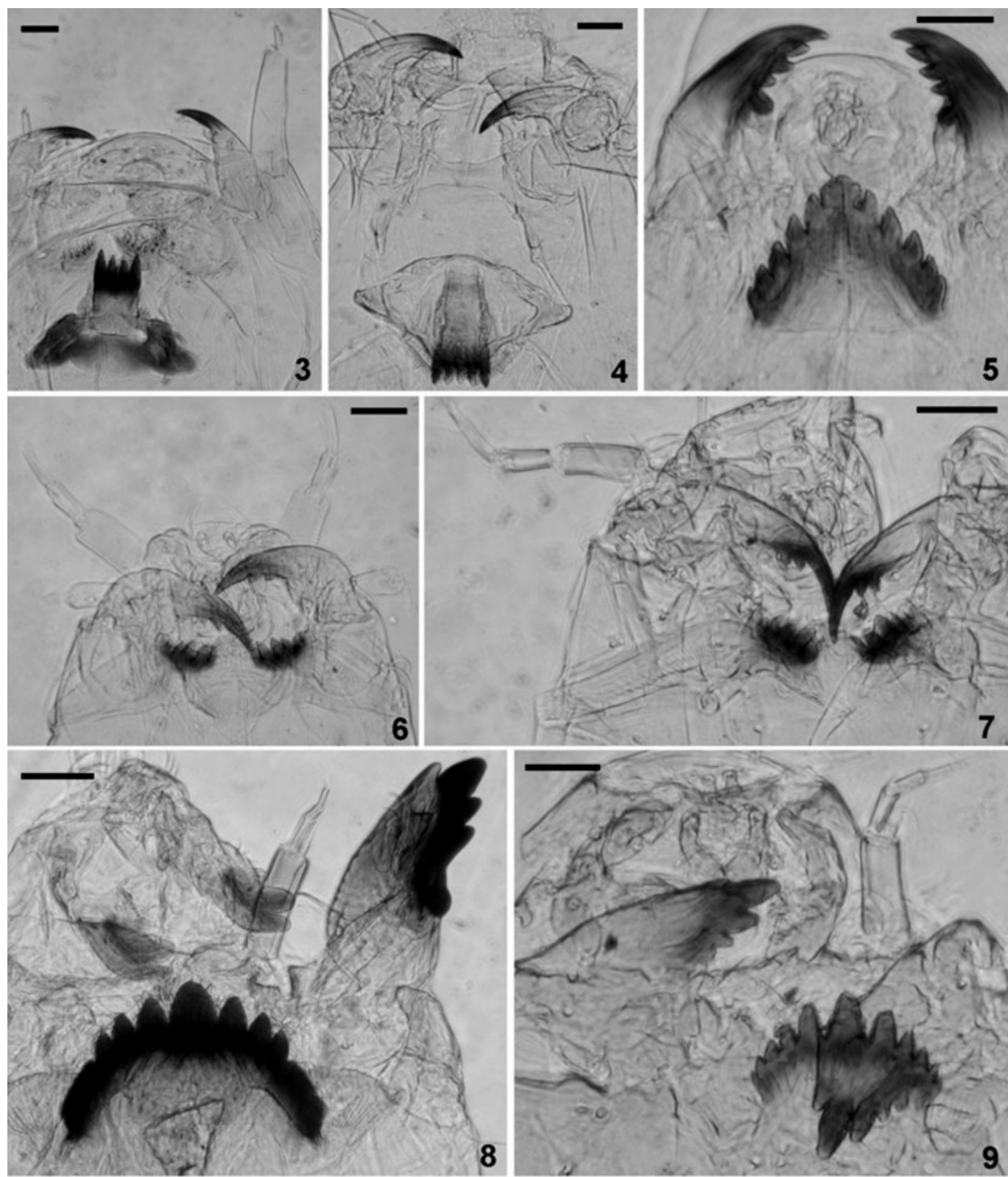

Figs 3-9. Head capsules of larval Chironomidae from Lake Tanganyika. 3, Procladius near brevipetiolatus 4, Ablabesmyia type Murusi; 5, Cricotopus type Tanganyika sp. 3; 6, Cryptochironomus type Tanganyika group 1; 7, Cryptochironomus type Tanganyika group 2; 8, Dicrotendipes cf. fusconotatus (Kieffer); 9, Dicrotendipes near sudanicus (Freeman). Scale bars $=25 \mu \mathrm{m}$.

parapods with numerous simple strong claws of variable length; and posterior parapods with at least 13 strong, sickle-shaped claws of which three are much darker than the others.

There are 11 known species of Ablabesmyia in sub-Saharan Africa, four of which have been partially described as living larvae (McLachlan 1969; Harrison 1991). An additional six larval types, which cannot be linked to any of the known species, have been defined on the basis of fossil material from Lake Tanganyika (two morphotypes; Eggermont \& Verschuren 2003a) and 
smaller East African crater lakes (four morphotypes; Eggermont \& Verschuren 2004a). Ablabesmyia type Murusi was found commonly in freshwater lakes across East Africa, but this is the first record from Lake Tanganyika.

Ablabesmyia larvae are predators-engulferspiercers of rotifers, microcrustaceans and other chironomids (Coffman \& Ferrington 1996); they frequently inhabit the littoral of lakes, but some species are reported from running waters. In African lakes, they are commonly found among nearshore-submerged weedbeds where densities of potential prey are high (Verschuren 1997). In the smaller East African lakes, fossil Ablabesmyia type Murusi was found commonly in lakes with abundant littoral vegetation (Eggermont 2004). The lone specimen in this study was found on Hydrilla verticillata at $10 \mathrm{~m}$ (Fig. 2), which marks the furthest extent of submerged vegetation on the Kigoma Bay depth transect.

\section{Subfamily Orthocladiinae}

\section{Cricotopus type Tanganyika sp. $3(n=2)$,}

\section{Fig. 5}

This taxon matches fossils cf. Cricotopus sp. 4 previously defined from Lake Tanganyika $(n=40$; figs 23-25 in Eggermont \& Verschuren 2003a). The revised diagnosis now includes the pecten epipharyngis, antenna and body parts, allowing definite assignment to the genus Cricotopus: the pecten epipharyngis consisting of three unserrated scales. Antenna short, with five consecutively smaller segments; first segment stout, $\sim 1.5$ times its own basal width, with ring organ in basal third; blade seated distally on the first antennal segment and shorter than the length of the flagellum. Anterior parapods bearing claws with both long simple teeth and shorter comb-like teeth; posterior parapods with an apical group of simple claws.

There are at least 19 African Cricotopus species (Freeman 1956), of which 6 have been described as living larvae including the two most widespread species, C. scottae Freeman and C. albitibia Walker (McLachlan 1969; Harrison 1992). Among the various distinct Cricotopus-like fossil morphotypes found in Lake Tanganyika (Eggermont \& Verschuren 2003a), one fully conforms to C. scottae as defined by Harrison (1992), whereas others, including cf. Cricotopus sp. 4, were suspected to represent a distinct class of worn $C$. scottae with damaged median and second lateral mental teeth (erroneously mentioned by Eggermont \& Verschuren (2003b) as damaged median and first lateral teeth). Diagnostic features revealed through this study argue that the latter assumption is plausible. Harrison (1992) also noted that the median teeth in the many Cricotopus specimens he examined were often worn down or broken. The fact that similar worn versions were lacking in 55 fossil Cricotopus specimens (including real C. scottae) from East African crater lakes, however, warrants retaining distinct morphotypes at this stage. The designation sp. 3 is used here to avoid confusion with the two previously described larval types from Tanganyika being $C$. scottae Freeman and C. cf. bicinctus group (Meigen) sp.

The genus Cricotopus includes shredder-herbivores and collector-gatherers; its larvae are found commonly in the littoral zone of lakes, where they are associated with vascular hydrophytes, though some representatives are lotic (Coffman \& Ferrington 1996). C. scottae is found commonly on shallow mud bottoms in weedbeds or flooded areas with terrestrial plants (McLachlan 1969; Dejoux 1973; Harrison 1987; Kribet \& Harrison 1989). In Lake Tanganyika, fossil Cricotopus type Tanganyika sp. 3 was significantly correlated with water depth, and its fossil distribution further revealed a preference for deep-water, organic mud bottoms poor in coarse plant debris and sand (Eggermont \& Verschuren 2003c). Of the two specimens examined here, one was found on medium sand lake bottom among aquatic plants at $5 \mathrm{~m}$ water depth, whereas the other was recorded on a very coarse-grained sand bottom in the shallow and unvegetated splash zone (Fig. 2).

\section{Subfamily Chironominae Tribe Chironomini}

\section{Cryptochironomus type Tanganyika group 1}

\section{$(n=1)$, Fig. 6}

This larval type was previously described based on variable fossil specimens from Lake Tanganyika ( $n=74$; figs $4-5$ in Eggermont \& Verschuren $2003 b$ ) and small and medium-sized crater lakes in tropical East Africa $(n=6.5$; figs $18-19$ in Eggermont \& Verschuren 2004b); it groups all Cryptochironomus species with ventromental plates about as wide as the mentum. The revised diagnosis now includes the seta subdentalis, the labral setae 1 (SI) and 2 (SII), antenna and body 
parts: Seta subdentalis short and pointed. SI and SII blade-like. Antenna with five tubular segments; first antennal segment $\sim 2.5$ times its basal width, shorter than the flagellum, with ring organ in distal third; second segment shorter than third segment, with blade arising from its distal half, reaching almost to the antennal apex; fourth and fifth segments small and inconspicuous. Anterior parapods with long, serrated claws; posterior parapods with simple claws.

At least eight Cryptochironomus species are known from equatorial Africa (Freeman \& Cranston 1980; Harrison 2000) of which four have been partly described as living larvae (McLachlan 1969; Harrison 1996). The two fossil morphotypes described from Lake Tanganyika and smaller East African lakes, namely $C$. type Tanganyika group 1 and 2, probably each include more than one species. The elaborate diagnosis for $C$. type Tanganyika group 1 provided here, hence, should not be generalized across all species belonging to this morphotype. The lone specimen in this study may be conspecific with C. lindneri (Freeman), keying out to C. type Tanganyika sp. 1 and known to possess a spatulate seta subdentalis and one antennal blade only.

Cryptochironomus larvae are known as predatorengulfers feeding on Protozoa, microcrustaceans, Oligochaeta, and other chironomids in the littoral and profundal zones of lakes; some representatives are lotic (Coffman \& Ferrington 1996). Cryptochironomus lindneri is known to roam welloxygenated open mud lake bottoms (McLachlan 1969; Petr 1972, Tudorancea et al. 1989). In Lake Tanganyika, fossil Cryptochironomus spp. did not display a significant relationship with any of the environmental gradients in bottom habitat, but their fossil distribution suggests some preference for deep-water, organic mud bottoms poor in coarse plant debris and sand (Eggermont \& Verschuren 2003c). The lone $C$. type Tanganyika group 1 specimen was found on medium-grained sand bottoms at $1 \mathrm{~m}$ water depth (Fig. 2).

\section{Cryptochironomus type Tanganyika group 2} $(n=5)$, Fig. 7

This larval type was previously described based on variable fossil specimens from Lake Tanganyika ( $n=9$; fig. 6 in Eggermont \& Verschuren 2003b), and from small and medium-sized crater lakes in tropical East Africa ( $n=1$; fig. 20 in Eggermont \& Verschuren 2004b) and West Africa $(n=5$; figs 23-25 in Eggermont et al. (2005)); it groups all Cryptochironomus with ventromental plates $>1.2$ times as wide as the mentum; the ventromental plates in the five specimens examined here were 1.4-1.8 times as wide as the mentum (on average 1.6 times). We also found the labral setae SI and SII, antenna, and body parts, which were all similar to C. type Tanganyika group 1, as described earlier. Given possible multiple species within this morphotype, this elaborate diagnosis should not be generalized across all these species.

In Lake Tanganyika, fossil Cryptochironomus spp. did not display a significant relationship with any of the environmental gradients in bottom habitat, but their fossil distribution did suggest some preference for deep-water, organic mud bottoms poor in coarse plant debris and sand (Eggermont \& Verschuren 2003c). Theunissen (1993) found live $C$. type Tanganyika group 2 specimens (identified as cf. Cryptochironomus sp. A) only at 30-35 m water depth, on fine-grained sediments. We found specimens of this morphotype on fine- to mediumgrained sand sediments at depths of 5, 10, and $20 \mathrm{~m}$, and also clinging to the Hydrilla verticillata sample taken from $10 \mathrm{~m}$ water depth (Fig. 2).

\section{Dicrotendipes cf. fusconotatus (Kieffer)}

\section{$(n=2)$, Fig. 8}

This larval type was previously described based on fossil specimens from Lake Tanganyika $(n=4$; figs 7-8 in Eggermont \& Verschuren 2003b; for a revised explanation of tooth homology among Dicrotendipes species, see Eggermont \& Verschuren $2004 \mathrm{~b})$. The revised diagnosis also includes the labral seta SI, antenna and body parts: SI with (at least seven) fringes. Antenna with 5 segments; first segment obout three times its basal width, longer than flagellum; third segment shorter than second and fourth segment; fifth segment inconspicuous and tapering to a sharp point; blade longer than second and third segment combined, and seated distally on the first segment. Ventral tubules absent; posterior parapods with sickle-shaped claws of variable length.

At least 15 Dicrotendipes are reported from equatorial Africa (Freeman \& Cranston 1980; Epler 1988) but only four have been described as larvae (based on live specimens: Contreras-Lichtenberg 1986, 1988; Epler 1988; Harrison 1993, 1996; based on fossil specimens: Verschuren 1997; Eggermont \& Verschuren 2004b). So far, none of these has been reported from Lake Tanganyika. Conversely, an 
additional three fossil types (including $D$. cf. fusconotatus and $D$. near sudanicus, see next section), which could not be linked with certainty to any of the known species, have so far only been recorded from Lake Tanganyika (Eggermont \& Verschuren 2003b).

Dicrotendipes larvae are known as collectorsgatherers-filterers, living on a variety of welloxygenated sediments in or near submerged weedbeds (littoral zone) (Coffman \& Ferrington 1996). In an earlier study of Lake Tanganyika, the two D. cf. fusconotatus specimens were found in sediments with coarse plant debris (Eggermont 1999), but given the low number it was not possible to statistically deduce habitat preference (Eggermont \& Verschuren 2003). In this collection, both living Dicrotendipes cf. fusconotatus specimens were found clinging to Hydrilla verticillata at $10 \mathrm{~m}$ water depth (Fig. 2).

\section{Dicrotendipes near sudanicus (Freeman)}

\section{$(n=1)$, Fig. 9}

This larval type was previously described based on fossil specimens from Lake Tanganyika $(n=3$; fig. 12 in Eggermont \& Verschuren 2003b). Since the latter description only included mentum and ventromental plates, we provide the full diagnosis here: Postoccipital margin dark brown. Mentum dark brown, with single median tooth and six pairs of lateral teeth; median tooth extending beyond the first laterals, clearly separated from them by a V-shaped incision, and having barely noticeable lateral incisions; second laterals small, fully fused with the first laterals so as to form no more than a notch on the side of the first laterals; third to sixth laterals normally developed, gradually diminishing in size. Ventromental plates compact fan-shaped, $\sim 0.7$ times the width of the mentum, with $\sim 23$ strial ridges, and a finely crenulated anterior margin. Mandible with pointed apical tooth, a pale dorsal tooth; three inner teeth of equal size, and a weakly developed mola; seta subdentalis spatulate but pointed, extending almost to the apex of the second inner tooth. Premandible with two blades of which the inner blade is larger than the outer blade and spatulate, and rounded subapical bumps. Pecten epipharynghis with $\sim 5-7$ robust blunt teeth; SI fringed. Antennae with five segments; first segment approximately equal in length to the flagellum, 3.4 times its basal width, with ring organ in basal half; second segment longer than third seg- ment; third and fourth segments about equally sized; fifthth segment small and tapering to a sharp point; blade seated distally on the first segment, being slightly shorter than the flagellum. Ventral tubules absent.

The lone specimen of this morphotype is similar to D. septemmaculatus (Becker) larvae described from various African lakes (based on live specimens: Epler 1988; Contreras-Lichtenberg 1988; Harrsion 1993; based on fossil specimens: Verschuren 1997; Eggermont \& Verschuren 2004b), and live D. sudanicus larvae described from Lake Kariba, Zimbabwe (Epler 1988). Both species are widespread throughout the Afrotropical Region. The tentative name designation used here reflects the reporting of adult $D$. sudanicus from the Democratic Republic of Congo side of Lake Tanganyika (Freeman 1975 ) and the lesser number of ventromental striae compared to D. septemmaculatus (22-26 vs 27-29; Epler 1988), but it remains unclear whether this difference is really species-specific or intraspecific variation.

Dicrotendipes sudanicus larvae are reported from submerged trees and weedbeds (McLachlan 1969; Harrison 1996); larvae of D. septemmaculatus are mainly found in weedbeds, and on shallow mud bottoms of lakes and slow-flowing rivers (Harrison 1987, 1993; Kibret \& Harrison 1989). In an earlier study of Lake Tanganyika, the lone $D$. near sudanicus specimen was found in sediments with coarse plant debris (Eggermont 1999), but given the low number it was not possible to statistically deduce habitat preference (Eggermont \& Verschuren 2003c). In this study, the live D. near sudanicus was found attached to Hydrilla verticillata at $10 \mathrm{~m}$ water depth (Fig. 2).

\section{Microchironomus type Tanganyika group}

\section{$(n=19)$, Fig. 10}

We define this larval morphotype to group the three related fossil Microchironomus types from Lake Tanganyika, known as Microchironomus near Larva 1 of Harrison (1996), M. type Tanganyika sp. 2, and M. type Tanganyika sp. $3(n=916$; figs 15-20 in Eggermont \& Verschuren 2003b); it was not found in fossil material from smaller East African lakes (Eggermont \& Verschuren 2004b). These three taxa were differentiated based on the general appearance of the mentum, the width of the median tooth, the position of the first laterals relative to the median tooth, and the compactness of the cluster of fourth to sixth laterals. Since the 

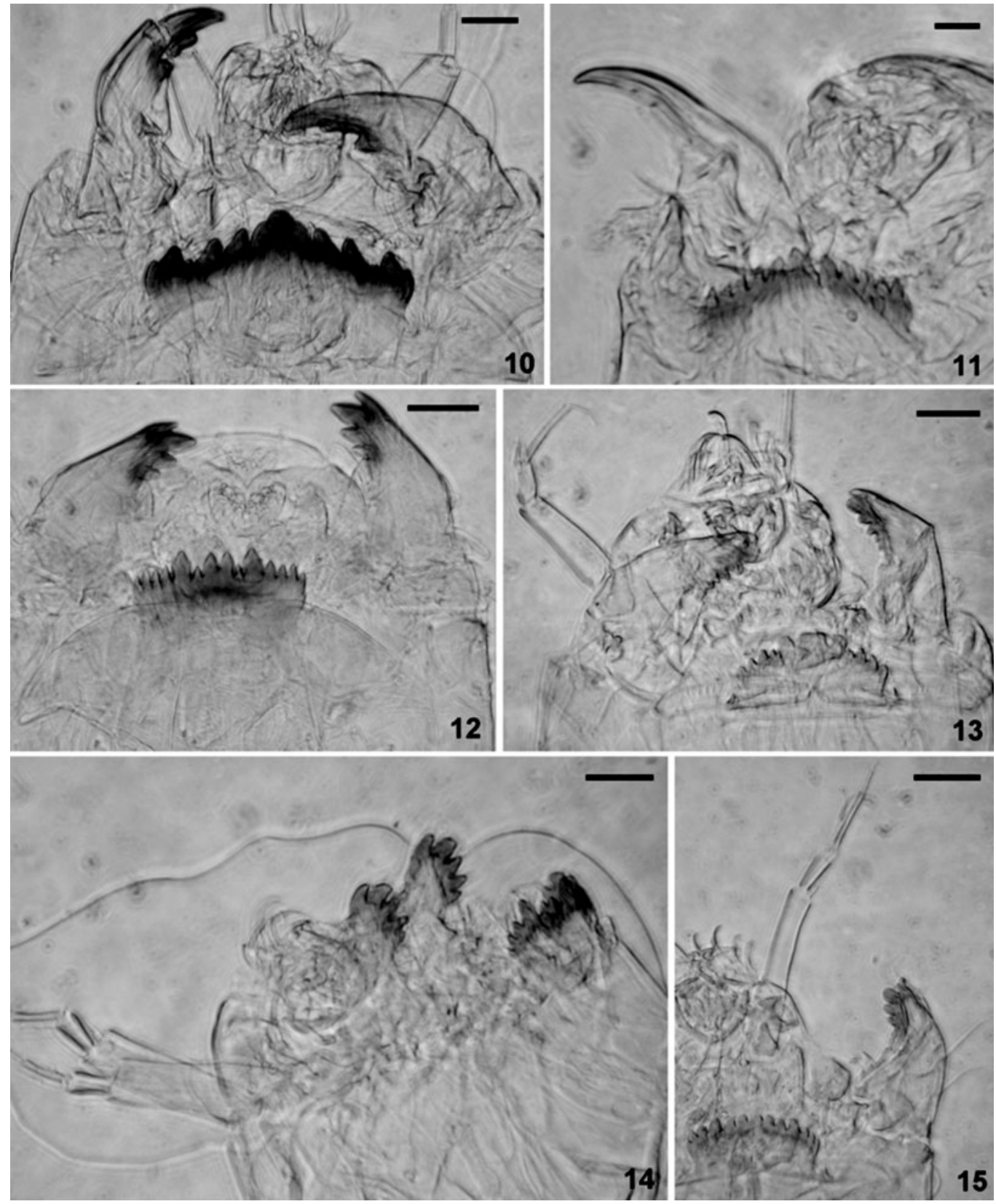

Figs 10-15. Head capsules of larval Chironomidae from Lake Tanganyika. 10, Microchironomus type Tanganyika group; 11, near Microchironomus type Tanganyika sp. 4; 12, Polypedilum near Larva type E of Harrison; 13, Cladotanytarsus mancus (Freeman) group sp. 1; 14, Cladotanytarsus group A of Pinder \& Reiss (1983) sp. 1; 15, Cladotanytarsus group A of Pinder \& Reiss (1983) sp. 2. Scale bars $=25 \mu \mathrm{m}$.

modern material revealed significant variability in the combination of these features, however, we now think these morphotypes belong to a single, highly variable (or variably worn) species: Mentum uniformly brown with six pairs of lateral teeth, sometimes triangular and compact; median tooth single and laterally notched, sometimes blunt, $\sim 1.2-2.0$ times the width of a first lateral; first 
laterals varying from being equally sized to second and third laterals to small and partially fused with the median; fourth to sixth laterals often compactly clustered together with tall fifth flanked by small fourth and sixth laterals, apices pointing inwards. Ventromental plates $\sim 0.8$ times the width of the mentum, weakly striated, with slightly crenulated margin. Mandible with an apical tooth about as long as the combined length of the two triangular inner teeth, and no dorsal tooth; seta subdentalis long and pointed, nearly reaching the first inner mandibular tooth, and placed well below the conspicuous mola. Premandible bifid with the outer tooth stiliform, narrower than the inner tooth. Pecten epipharyngis consisting of three scales. Antennae with five segments; first segment $\sim 2.4$ times its basal width and longer than the flagellum, ring organ located in basal half; third to fifth segments small (their combined length less than second segment); blade seated distally on the first segment, reaching to the antennal apex. Anterior parapods with fine and simple claws; posterior parapods simple and hook-like.

There are four known species of Microchironomus (Pinder \& Reiss 1983), three of which are widely distributed throughout the Palaearctic and Afrotropical regions (Freeman \& Cranston 1980; Cranston \& Judd 1989). The live larvae of all three species have been at least partially described (Dejoux 1971; Kugler 1971; Moller-Pillot 1984b), but present descriptions do not allow us to unambiguously assign Microchironomus type Tanganyika to any of these (for full comparison with possibly related species, see Eggermont \& Verschuren $2003 b)$. The present morphotype differs from fossil Microchironomus type East Africa group (Eggermont \& Verschuren 2004b), common in the smaller East African lakes, in possessing welldeveloped triangular instead of flattened inner mandibular teeth.

Microchironomus species are known as collectorgatherers in sandy littoral environments (Coffman \& Ferrington 1996). Harrison (1996) dredged (unassociated) Microchironomus larvae from unvegetated bottom sediments between 4 and $10 \mathrm{~m}$ water depth in Ethiopian lakes Ziway and Chamo, and from submerged weedbeds in Lake Awassa. In Lake Tanganyika, fossil Microchironomus types were recorded from a variety of sediments, but their fossil distribution did reveal a preference for shallow-water sediments rich in coarse plant debris and sand (Eggermont \& Verschuren 2003c). In the present study, live Microchironomus type Tanganyika were found in 3-20 m water depth, being most abundant on medium sand bottoms at $5 \mathrm{~m}$ water depth (Fig. 2). None of the specimens was found on the Hydrilla verticillata sample, but many were found on bottom sediments in the vicinity of macrophytes (Hydrilla verticillata and Potamogeton spp.)

\section{near Microchironomus type Tanganyika sp. 4}

\section{$(n=2)$, Fig. 11}

This larval type was previously described based on fossil specimens from Lake Tanganyika $(n=28$; figs 21-22 in Eggermont \& Verschuren 2003b). The revised diagnosis now includes the antenna and body parts: Antenna with five segments; first segment shorter than the flagellum, $\sim 2.5$ times its basal width; second segment slightly shorter than the first segment, $\sim 2$ times the combined length of the third to fifth segment; third and fourth segments about equal in length; fifth segment small; blade (and accessory blade?) seated distally on the first segment, not extending beyond the apex of the second segment. Anterior parapods with fine and simple claws; posterior parapods with simple and hooklike claws.

Despite the lack of characteristic clustering of the fourth to sixth lateral mental teeth, most features reveal a close relationship with Microchironomus (for details see Eggermont \& Verschuren 2003b). So far, this morphotype has not been encountered in fossil material from smaller East African lakes (Eggermont \& Verschuren 2004b). In Lake Tanganyika, fossils near $M$. type Tanganyika sp. 4 did not display a significant relationship with any of the environmental gradients in bottom habitat, but their fossil distribution did reveal some preference for shallow-water sediments rich in coarse plant debris and sand (Eggermont \& Verschuren 2003c). Theunissen (1993) found live specimens of $M$. type Tanganyika (identified therein as $c f$. Microchironomus sp. A) only at 10-13 m water depth. In this study, both live specimens were recorded in medium-grained sand bottoms at $30 \mathrm{~m}$ water depth (Fig. 2).

\section{Polypedilum near Larva type E of Harrison (1996) $(n=4)$, Fig. 12}

This larval type was previously described based on variable fossil specimens from Lake Tanganyika ( $n$ = 41; figs 35-36 in Eggermont \& Verschuren 
2003b) and from small- and medium-sized crater lakes in tropical East Africa $(n=6$; fig. 73 in Eggermont \& Verschuren 2004b). The revised diagnosis now also includes the antenna and body parts: antennae with five segments; first segment $\sim 2.5$ times its basal width; second segment smaller, about as long as fourth segment; third segment reduced to a small disc; fifth segment reduced to a small knob. Anterior and posterior parapods with small, (simple) sickle-shaped claws.

At least 40 Polypedilum species have so far been reported from the equatorial region of Africa (Freeman \& Cranston 1980; Oyewo \& Sæther 1998; Sæther \& Sundal 1998) of which nine have been (partly) described as larvae (McLachlan 1969; Lehman 1979; Dejoux 1971; Oyewo \& Sæther 1998). In addition, some 20 distinct, live and fossil types of unassociated Polypedilum larvae are reported from East African lakes. This larval type differs from the true (live) Polypedilum Larva type E of Harrison (1996) only in the height of the fourth laterals in relation to the fifth laterals, a disparity that may merely be a result of wear.

Polypedilum larvae display diverse feeding behavior (shredder-herbivores, collector-gatherers and predators), and are found commonly in association with vascular hydrophytes in the littoral zone of lakes. Polypedilum Larva type E of Harrison (1996) is reported on muddy bottoms near and under weedbeds in shallow waters of Lake Awasa (Harrison 1996). In Lake Tanganyika, fossil Polypedilum Larva type E of Harrison (1996) did not display a significant relationship with any of the environmental gradients in bottom habitat, but their fossil distribution did reveal some preference for shallow-water sediments rich in coarse plant debris and sand (Eggermont \& Verschuren 2003c). In this study, it was found at 3 and $5 \mathrm{~m}$ water depth in weed beds with medium-grained sand sediment (Fig. 2).

\section{Tribe Tanytarsini}

\section{Cladotanytarsus mancus (Freeman) group sp. $1(n=3)$, Fig. 13}

This larval type was previously described based on fossil specimens from Lake Tanganyika $(n=$ 136; figs 59-61 in Eggermont \& Verschuren 2003b). The revised diagnosis also includes body parts: anterior parapods with simple claws; posterior parapods with both simple and finely serrated claws; in the latter, the small teeth are placed in a single row.

There are six Cladotanytarsus species reported from equatorial Africa (Freeman \& Cranston 1980; Lehman 1979, 1981; Ekrem 1999), but only the larva of C. pseudomancus (Goetghebuer) has been described (based on live specimens: McLachlan 1969; based on fossil specimens: Verschuren 1997; Eggermont \& Verschuren 2004b). The present morphotype has not been reported from smaller East African lakes and closely resembles C. pseudomancus, which is widespread in East African lakes except for the spur on the antennal pedestal which is rather atypical for the genus Cladotanytarsus (as defined by Wiederholm 1983). The presence of both simple and single-row serrated claws on the anal parapods, however, is a feature unique among Tanytarsini (Wiederholm 1983; Epler 2000), strongly suggesting that this larval type indeed belongs to Cladotanytarsus.

Cladotanytarsus larvae are known as collectorgatherers-filterers in the vegetated littoral zone of lakes; the genus also includes lotic representatives (Coffman \& Ferrington 1996). In Africa, Cladotanytarsus is reported frequently from nearshore, well-oxygenated areas with fine to coarse sand sediment (e.g. McLachlan 1969; Petr 1972; Tudorancea \& Harrison 1988). In an earlier study in Lake Tanganyika, fossil C. mancus (Freeman) group sp. 1 was significantly correlated with water depth, and its fossil distribution further revealed a preference for deep-water, organic mud bottoms poor in coarse plant debris and sand (Eggermont \& Verschuren 2003c). The present larval type was found at one and $30 \mathrm{~m}$ water depth in mediumgrained sand sediment (Fig. 2).

\section{Cladotanytarsus group A of Pinder \& Reiss \\ (1983) sp. $1(n=1)$, Fig. 14}

This larval type was previously described based on fossil specimens from Lake Tanganyika $(n=$ 217; figs 55 to 58 in Eggermont \& Verschuren $2003 b)$. The revised diagnosis now includes a more detailed description of the premandible, antenna, and body parts: Premandible with at least three teeth. Antennal pedestal short, without a spur. Antenna with five segments: first antennal segment $\sim 3.5$ times its basal width, approximately equal to the length of the flagellum, with blade seated distally and ring organ at proximal end; second segment wedge-shaped, shorter than third segment; fourth segment longer than fifth, but 
both are small; Lauterborn organs on short pedicels seated distally on the second segment. Anterior parapods with simple claws; posterior parapods with both simple and finely serrated, sickle-shaped claws; in the latter, the small teeth some of which are quite long - are placed in a single row.

This morphotype has not been encountered in fossil material from smaller East African lakes (Eggermont \& Verschuren 2004b). In Lake Tanganyika, fossil Cladotanytarsus group A of Pinder \& Reiss (1983) sp. 1 was significantly correlated with water depth, and its fossil distribution further pointed to a preference for deep-water, organic mud bottoms poor in plant debris (Eggermont \& Verschuren 2003c). The single live specimen in this study was found in coarse-grained sand sediment in the splash zone (Fig. 2).

\section{Cladotanytarsus group A of Pinder \& Reiss (1983) sp. $2(n=11)$, Fig. 15}

This larval type was previously described as Tanytarsini indet. sp. 1 based on fossil specimens from Lake Tanganyika ( $n=200$; figs $70-72$ in Eggermont \& Verschuren 2003b). The revised diagnosis now includes the labral setae SI and SII, a more detailed description of the antenna and body parts, which argue for inclusion in the genus Cladotanytarsus (see below): SI comb-like, bases fused; SII simple, set on tall pedestals. Antennal pedestal tubular, with a short spur. Antennae with five segments: first segment longer than the flagellum, $\sim 5$ times its basal width, blade seated distally being approximately half the length of the second segment; second segment clearly shorter than the third segment and somewhat wedgeshaped; fourth segment longer than fifth segment, but both small; Lauterborn organs typical, consisting of three or more seta-like branches arising from a common base seated distally on the second segment, length of branches equal to or greater than the third segment. Anterior parapods with simple claws; posterior parapods with both simple and finely serrated, sickle-shaped claws; in the latter, the small teeth - some of which are quite longare placed in a single row.

Except for the small spur on the antennal pedestal, this taxon fully conforms to Cladotanytarsus group A of Pinder \& Reiss (1983), based on the first laterals being smaller than median tooth and second laterals. This larval type has not been reported from smaller East African lakes. In Lake Tanganyika, fossil Cladotanytarsus group A of Pinder \& Reiss (1983) sp. 2 was significantly correlated with water depth, and its fossil distribution further pointed to a preference for deep-water, organic mud bottom, poor in plant debris (Eggermont \& Verschuren 2003c). Theunissen (1993) found live Cladotanytarsus group A of Pinder \& Reiss (1983) sp. 2 (identified therein as cf. Cladotanytarsus sp. A) in the splash zone $(0-5 \mathrm{~m})$ and, most abundantly, at $20-25 \mathrm{~m}$ water depth. In this study, all three specimens were recorded on medium-grained sand sediment at $30 \mathrm{~m}$ water depth (Fig. 2).

\section{Tanytarsini indet. type Tanganyika sp. 3

$$
(n=38) \text {, Fig. } 16
$$

This larval type was previously described based on fossil specimens from Lake Tanganyika $(n=$ 394; figs 74-76 in Eggermont \& Verschuren 2003b). The revised diagnosis now also includes the labral setae, a more detailed description of the antenna, and body parts: Premandible with 3-5 teeth. SI comblike, bases fused; SII set on tall pedestals. Antennal pedestal drawn out into a very tall, blunt spur. Antenna with five segments; first antennal segment $\sim 3.8$ times its basal width, slightly shorter than the flagellum; second segment cylindrical, shorter than both the first and third segment, with distal blade being longer than the second segment; third segment $\sim 2 / 3$ times the length of the first segment; fourth segment longer than the fifth segment, but both small; style and Lauterborn organs on short stalks seated distally on the second segment. Anterior parapods with simple claws; posterior parapods with both simple and finely serrated, sickle-shaped claws; in the latter, the small teeth - some of which are quite long - are placed in a single row.

The elongated antennal pedestal, unusually large antennal spur and the cylindrical second antennal segment resembles Tanytarsus, but the unique combination of both simple and singlerow serrated parapod claws is typical for Cladotanytarsus; hence, the generic assignment of this taxon is uncertain. In Lake Tanganyika, fossil Tanytarsini indet. type Tanganyika sp. 3 was significantly correlated with water depth, and its fossil distribution further pointed to a preference for deep-water organic mud bottoms, poor in plant debris (Eggermont \& Verschuren 2003c). In this study, it was recorded between one and $20 \mathrm{~m}$ on fine- and medium-grained sand sediment, but most abundantly on Hydrilla verticillata (Fig. 2). So 

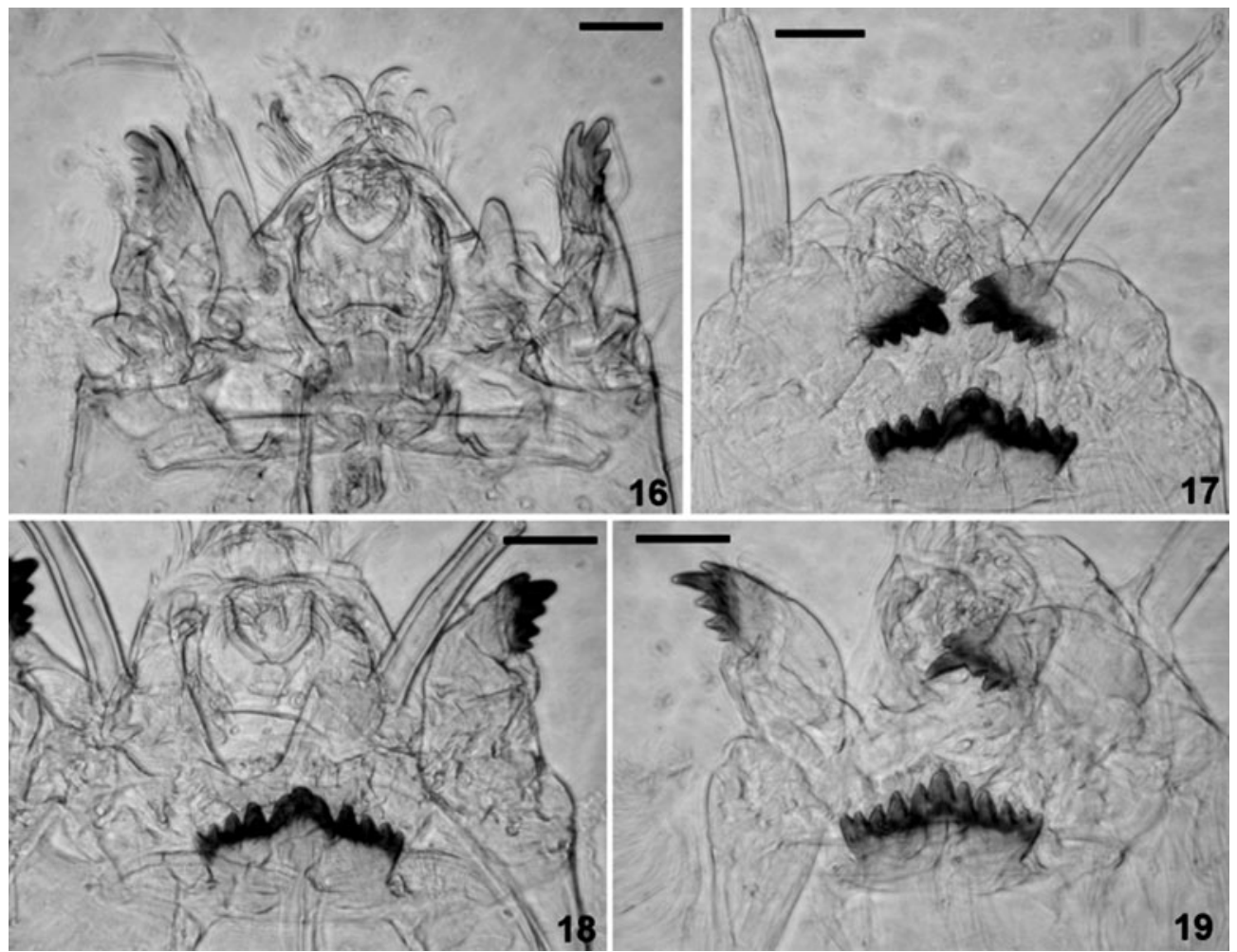

Figs 16-19. Head capsules of larval Chironomidae from Lake Tanganyika. 16, Tanytarsini indet. type Tanganyika sp. 3;17, 18, Tanytarsini indet. type Tanganyika sp. 6; 19, Tanytarsini indet. type Tanganyika sp. 7. Scale bars $=25 \mu \mathrm{m}$.

far, it has not been reported from smaller East African lakes.

\section{Tanytarsini indet. type Tanganyika sp. 6 $(n=13)$, Figs $17-18$}

This larval type was previously described based on fossil specimens from Lake Tanganyika ( $n=77$; figs 80-82 in Eggermont \& Verschuren 2003b). The revised diagnosis now includes the labral setae, a more detailed description of the mandible, antenna, and body parts: two mandibular setae present in unworn specimens; seta subdentalis long and curved. SI comblike, with bases fused; SII set on tall pedestals; labral lamellae well developed. Antennal pedestal possibly without a spur (erroneously mentioned as having a spur in Eggermont \& Verschuren 2003b). Antennae with first segment $\sim 5$ times its basal width; second and third segments are approximately equal in length; fourth segment $\sim 3$ times the length of the fifth segment; Lauterborn organs on very long stalks seated distally on the second segment, extending well beyond the fifth segment; blade seated dis- tally on the first segment, longer than the second segment. Anterior parapods with small, fine and simple claws; posterior parapods with small, stout and hooklet claws. This morphotype is very similar to Tanytarsus in all characters except for the length of the second antennal segment being smaller, not equal to or longer than the third to fifth segment combined.

In Lake Tanganyika, fossil Tanytarsini indet. type Tanganyika sp. 6 was significantly correlated with water depth, and its fossil distribution further revealed a preference for deep-water, organic mud bottoms poor in plant debris (Eggermont \& Verschuren 2003c). With the exception of two larvae found at one and $3 \mathrm{~m}$, the remaining 11 specimens of this morphotype were found clinging to the macrophyte Hydrilla verticillata in Kigoma Bay (Fig. 2).

\section{Tanytarsini indet. type Tanganyika sp. 7}

$$
(n=21) \text {, Fig. } 19
$$

This larval type was previously described based on fossil specimens from Lake Tanganyika $(n=$ 
134; figs 83-85 in Eggermont \& Verschuren 2003b). The revised diagnosis now includes the labral setae, a more detailed description of the mandible, antenna, and body parts: SI feather-like, bases fused; SII simple and set on tall pedestals. Mandible with one dorsal tooth, a strong apical tooth and three inner teeth of which the third is small; an accessory dorsal tooth is sometimes visible. Antennal pedestal with a short spur. Antennae with five segments; first segment is $\sim 5$ times its basal width; second and third segments are approximately equal in length; fourth segment $\sim 3$ times the length of the fifth segment; blade seated distally on the first segment, about equal in length to the second and third segment combined; Lauterborn organs pointed, set on pedicels longer than the combined length of the third to fifth segments. Anterior parapods with small, fine and simple claws; posterior parapods with small, stout and hooklet claws.

This morphotype is very similar to Tanytarsus in all characters except for the length of the second antennal segment being smaller, not equal to or longer than the third to fifth segment combined. In Lake Tanganyika, fossil Tanytarsini indet. type Tanganyika sp. 7 was not significantly correlated with any of the environmental gradients in bottom habitat, but its fossil distribution did reveal a preference for deep-water, organic mud bottoms poor in coarse plant debris and sand (Eggermont \& Verschuren 2003c). Theunissen (1993) found live specimens of this larval type (therein identified as cf. Tanytarsus sp. A) to be concentrated at water depths between 0 and $13 \mathrm{~m}$. This morphotype was found in all sample sites from three to $30 \mathrm{~m}$ water depth, including the Hydrilla verticillata sample (Fig. 2). So far, it has not been recorded from the smaller East African lakes.

\section{Faunistics and chironomid depth distribution}

The chironomid community along the depth transect is clearly dominated by Chironominae (13 taxa; $85.8 \%$ of total live abundance), with the Tanytarsini being most strongly represented (six taxa; $61.7 \%$ of total abundance). In contrast, Tanypodinae (two taxa; $12.7 \%$ of total abundance) and Orthocladiinae (one taxon; $0.01 \%$ of total abundance) make up only a minor fraction of the fauna. The six most abundant morphotypes (Tanytarsini indet. type Tanganyika sp. 3, Tanytarsini indet. type Tanganyika sp. 7, Microchironomus type Tanganyika group, Procladius near brevipetiolatus, Tanytarsini indet. type Tanganyika sp. 6 and Cladotanytarsus group A of Pinder \& Reiss sp. 2) account for $85.1 \%$ of total chironomid abundance. The highest chironomid density, raw taxon richness, and alpha diversity were found at the 3 and $5 \mathrm{~m}$ sample stations (1443 specimens $/ \mathrm{m}^{2}$, six taxa, 1.64 and 1819 specimens $/ \mathrm{m}^{2}$, eight taxa, 1.72 respectively; Fig. 2). By comparison, abundance and diversity were all substantially lower at the adjacent 1 and $10 \mathrm{~m}$ sample stations ( 941 specimens $/ \mathrm{m}^{2}$, four taxa, 0.69 and 1255 specimens $/ \mathrm{m}^{2}$, five taxa, 1.33 respectively; Fig. 2). A presence-absence comparison of the Hydrilla verticillata sample versus the $10 \mathrm{~m}$ transect sample showed a fairly similar number of taxa present on the macrophyte itself (six taxa) and in the surrounding medium sand sediment (five taxa), but with only three taxa in common.

The chironomid community in Kigoma Bay is dominated by a few species of chironomine detritus and alga feeders concentrated in areas of high macrophyte density, with a small component of predatory Tanypodinae taxa, along with several additional taxa of both subfamilies. These are relatively rare and possibly habitat-specific.

\section{DISCUSSION}

\section{Taxonomic diversity}

The pattern of high species diversity among other components of Lake Tanganyika's aquatic fauna (Coulter 1991) apparently extends to its midge community as well: Eggermont \& Verschuren $(2003 a, b)$ found 77 morphotypes in a relatively modest collection of 3812 fossil specimens, and Theunissen (1993) found 20 taxa in a small collection of 169 live specimens collected from the lake itself, 15 of which are conspecific to fossil Tanganyika types. This rich fauna of 83 distinct morphotypes, including one additional taxon recorded in this study, represents the largest among any studied African lake or reservoir, with the exception of the 93 species found in light-trap sampling of Lake Chad by Dejoux (1968). Furthermore, a comprehensive examination of subrecent deposits in 66 low and mid-elevation freshwater lakes in Uganda, Kenya, Tanzania, and Ethiopia found a combined fossil fauna containing 79 taxa, only two more than collected from a small number of localities in Lake Tanganyika, among more than twice as many specimens. This suggests that benthic habitat diversity in Lake Tanganyika approaches 
overall benthic habitat diversity presented by the entire range of smaller East African freshwater lakes (see Eggermont \& Verschuren 2004b).

Although comparable to other live sampling efforts in African lakes - Lakes Kariba (34 taxa) and Volta (21 taxa) (McLachlan 1969; Petr 1971) - the number of taxa recorded along the Kigoma Bay depth transect is relatively low compared to the fossil inventory (16 taxa or $19.3 \%$ of Tanganyika's midge diversity). We attribute this to two factors. First, our current study involved a much lower sampling effort focused on onlyonemajor habitat type (sandy lake bottom) in Kigoma Bay. By contrast, the 36 surface-sediment samples analysed in Eggermont \& Verschuren $(2003 a, b)$ were collected from a broad range of depths among a variety of sediment types, bottom slopes, and oxygen regimes throughout the northeastern part of Lake Tanganyika. Second, sampling of living chironomids records the local fauna only, whereas fossil assemblages represent temporally and spatially averaged assemblages (Frey 1988). Hence, a full comparison between live and fossil studies would require the collection of a similarly averaged sample, both temporally (at least one annual cycle) and spatially (i.e., an equivalent range of habitats should be represented).

\section{Chironomid depth distribution}

With the exception of sediment TOC concentration, grain size and macrophyte presence, no other distinct patterns emerged for environmental variables along the depth transect; the ranges for these data are relatively small (Table 1 ). As a meromictic lake, Lake Tanganyika is constantly stratified and the waters above the oxycline in Kigoma Bay remain mixed and well oxygenated (80-100 m; Degens et al. 1971), especially during the windy season (May-September). This environmental homogeneity between most sample stations, along with the small sample size for many chironomid morphotypes makes drawing definitive inferences between environmental variables and specific taxa problematic; however, it is still possible to discern several important trends from the data.

The highest chironomid density, raw taxon richness, and alpha diversity were found at the 3 and $5 \mathrm{~m}$ sample stations (Fig. 2). We observed corresponding peaks in the number, size, and density of submerged macrophytes at these two depths and strongly suspect a causal relationship between the two. Macrophyte communities gener- ally have greater habitat complexity for aquatic invertebrates than surrounding areas devoid of plants (Pinder 1995; Tokeshi 1995). Direct larval consumption of live plant tissue may be limited to a relatively small number of chironomid species. However, detritus (including plant detritus) is the most common food ingested by chironomids, as assessed by gut content analysis (Berg 1995). Moreover, coarse plant detritus preferred by shredders is found in greatest abundance in the vicinity of macrophyte beds. Macrophyte communities also attract an assortment of such prey organisms as suspended diatoms, which are a major food source for filter feeding chironomids, with recently sedimented algae being an important food for collector-gatherer species (Berg 1995). The variety of feeding niches available in the macrophyte zone (both on the plants and in the surrounding sediments), therefore, can support chironomids from an assortment of trophic guilds. Among the genera recorded from the 3 and $5 \mathrm{~m}$ samples, we found collector-gatherers (Cricotopus, Cladotanytarsus, Dicrotendipes, Microchironomus, Polypedilum), collector-filterers (Cladotanytarsus, Dicrotendipes), shredders-herbivores (Cricotopus, Polypedilum) and predator-engulfers (Ablabesmyia, Cryptochironomus, Procladius, Polypedilum). All are known either as sprawlers-burrowers in sandy lentic habitats or clingers associated with vascular hydrophytes (Coffman \& Ferrington 1996).

By comparison, measures of abundance and diversity were all substantially lower at the adjacent one and $10 \mathrm{~m}$ sample stations where macrophyte communities were either nonexistent or very sparse, respectively. Presumably, this is due to wave-induced lake bottom instability at shallow depths and diminished sunlight penetration at $10 \mathrm{~m}$ and deeper. Meanwhile, lake bottom substrate and all other measured environmental factors were similar between the vegetated and unvegetated sites. This supports our hypothesis that, at least at the small spatial scale of our Kigoma Bay study area, larval distribution is linked to macrophyte density. In sum, we propose that higher larval density and taxon diversity in fossil assemblages, particularly among Tanytarsini indet. types, Microchironomus, Polypedilum, and Procladius, may be indicative of sandy or vegetated littoral palaeoenvironments in Lake Tanganyika. This is further supported by the fossil distribution pattern of these taxa, which points to a preference for shallow-water sediments rich in coarse plant 
debris and sand (Eggermont \& Verschuren 2003c).

We found the macrophytes themselves to support a more diverse chironomid community, dissimilar in species composition compared to the surrounding sediments. This trend is generally true for chironomids in both lentic and lotic environments (Tokeshi 1995), particularly for such soft bottoms as sand (Pinder \& Reiss 1983). Three of the taxa recorded from the Hydrilla verticillata sample, Ablabesmyia type Murusi, Dicrotendipes cf. fusconotatus, and Dicrotendipes near sudanicus (Freeman), were not encountered at any other transect depth. All belong to genera strongly associated with aquatic plants in other East African lakes as well (Epler 1988; Harrison 1996; McLachlan 1969; Verschuren 1997; Eggermont 2004). Therefore, we consider these three morphotypes to be strong candidates for direct inference of palaeovegetation and littoral zone conditions in Lake Tanganyika. Tanytarsini indet. types 3,7 , and especially 6 , although they were not exclusively found on plants themselves, may also be indicative for these conditions.

Although they seem to show preference for vegetated habitat, several morphotypes may be considered generalist species based on their presence along wide ranges of the depth transect, including Tanytarsini indet. type Tanganyika sp. 3 (which is the most abundant taxon in this collection), Microchironomus type Tanganyika group, Tanytarsini indet. type 6, and Procladius near brevipetiolatus Goetghebuer. Although known primarily as predators, some species within the latter genus are known as free-ranging, facultative omnivores in a variety of depths and habitats (Berg 1995; Pinder 1995).

Of the four morphotypes recovered from the $30 \mathrm{~m}$ sample (Tanytarsini indet. type Tanganyika sp. 7, Cladotanytarsus mancus (Freeman) group sp. 1, Cladotanytarsus group A of Pinder \& Reiss (1983) sp. 2, near Microchironomus type Tanganyika sp. 4; Fig. 2), the latter two were found at this depth exclusively. Both belong to genera that are primarily collectors of organic detritus, and their presence here may be related to high TOC, which peaks at $30 \mathrm{~m}$, along with turbidity. Near Microchironomus type Tanganyika sp. 4 was observed in insufficient numbers to draw conclusions, but its live distribution in Bujumbura Bay (Theunissen 1993) and its fossil distribution along the eastern shore of the lake (Eggermont \& Verschuren 2003c) strongly suggest its utility as a palaeoindicator of littoral or sublittoral environments. All eleven specimens of Cladotanytarsus group A of Pinder \& Reiss sp. 2, on the other hand, were recovered from this depth, suggesting a strong relationship between this morphotype and environmental conditions at $30 \mathrm{~m}$, including high levels of suspended and sedimented organic matter. This is also supported by the fossil distribution pattern of this taxon pointing to a preference for deep-water, organic mud bottom poor in plant debris (Eggermont \& Verschuren 2003c).

The complete absence of any chironomids in the 50 and 80-m samples was somewhat puzzling, given the physiological and behavioral adaptations of some genera to low-oxygen conditions. We attribute this to the well-known occurrence of low larval density in profundal sediments (Pinder 1995). Theunissen (1993) only found some 40 larvae $/ \mathrm{m}^{2}$ at $64 \mathrm{~m}$ water depth, and Eggermont \& Verschuren $(2003 \mathrm{a}, \mathrm{b})$ recorded only one Stictochironomus and seven Chironomus larvae in a collection of 3812 specimens. Greater sampling effort may have revealed these and other rare profundal taxa that are valuable as indicators of deep-water environments in sediment-core-fossil assemblages. Nevertheless, we believe that the inverse relationship between larval density and depth evident along the Kigoma Bay depth transect between five and $80 \mathrm{~m}$ (Fig. 2) demonstrates that overall fossil abundance in Lake Tanganyika sediment core layers can be utilized as a proxy for palaeo-water depth and, thus, lakelevel fluctuations.

\section{Live versus fossil faunas}

Transfer functions are usually based on fossil remains to take into account taphonomic processes and sediment dynamics, which also affect the palaeorecord (e.g. Battarbee \& Flower 1984; Charles et al. 1991). Moreover, fossil assemblages have the advantage that it is easier to (1) obtain a sufficient sample size for statistical analysis, (2) overcome some of the logistic difficulties associated with the monitoring of live aquatic invertebrate populations (for details see Rumes et al. 2005), and (3) provide a spatially and temporally integrated view of present-day invertebrate species diversity and community structure (Frey 1988; McKinney 1991). Nevertheless, besides relating ecological data to specific larval morphotypes (and, thus, fossil morphotypes), examination of the lake's live midge fauna has other significant benefits for 
palaeoecologically-oriented investigations. First, key diagnostic features on the head capsule are generally better preserved on live specimens than on fossil specimens. They can, therefore, be used to improve larval descriptions and to resolve issues of taxonomic uncertainty typical of fossil studies. We now have found the antennae (which is a key diagnostic head part but has the lowest preservation potential), body parts (mainly anterior and posterior parapods), or labral elements of all recovered taxa, elucidating some taxonomic relationships. For example, fossil cf. Cricotopus sp. 4 could now be attributed with certainty to the genus Cricotopus, and fossil Tanytarsini indet. type 1 could be assigned to Cladotanytarsus group A of Pinder \& Reiss (1983). Similarly, the diagnosis of fossil Dicrotendipes near sudanicus (Freeman), which previously only included the mentum and ventromental plates, has been improved to contain descriptions of the mandible, labrum, antennae and body. Despite these improvements, most taxa in this study are still defined to provisional species or species groups within known genera. Yet, this is largely unavoidable since the vast majority of African chironomid species have not been described as larvae in direct association with the adults. As such, the majority of our morphotypes are probably the undescribed larvae of known and named species, however some of them may actually represent new species. In either case, all morphotypes described here are clearly distinguishable from each other on the basis of differences in key diagnostic features. From the perspective of climate and ecological reconstructions, true taxonomic identity is secondary in importance as long as down-core identifications are done in a consistent way.

Second, study of live specimens can help to assess the quality of fossil-based taxonomy, and therefore, the extent to which ecological information retrieved from live specimens can be transferred to palaeoenvironmental studies (i.e. the degree of compatibility between ecological data derived from living and fossil assemblages). Except for the grouping of the three related Microchironomus types recognized in fossil material into a single, highly variable taxon, the taxonomic resolution reached in this study is fully matched by the fossilbased taxonomy of Eggermont \& Verschuren (2003a,b); none of the previously defined fossil types could be unequivocally split up into different species. Even such presumed group taxa as
Cryptochironomus type Tanganyika sp. 2 are preferably kept as a unit because it remains unclear to what extent the recovered features (like the shape of the seta subdentalis) are really species-specific and not prone to intraspecific variation. Similarly, 15 of the 20 taxa distinguished in the live study of Theunissen (1993) are conspecific to a single larval type encountered in the fossil collection of Eggermont \& Verschuren (2003a,3b); the remaining five did not show any similarity with fossil types and are, thus, considered to be clearly distinct. Moreover, taxonomic conclusions based on fossil material still seem to stand firm, and so they did not result from deficiencies in fossil-based taxonomy. For example, based on their fossil specimens, Eggermont \& Verschuren (2003b) stated that the descriptions of several genera available at the time needed broadening to accommodate all African representatives. It is clear from our study that the definition of Cladotanytarsus (cf. Wiederholm 1983) needs to be expanded to incorporate species with a spur on their antennal pedestal. Meanwhile, Cladotanytarsus with blunt spurs on the antennal pedestals have also been reported in the Palaearctic (Brooks et al. 2007). Given that taxonomic resolution in our live and fossil studies is highly compatible, ecological knowledge gathered from studying lakes' living fauna can immediately be applied to palaeoenvironmental studies. Furthermore, this study suggests that taxonomic resolution currently achieved in African chironomid palaeoecology is of a sufficiently high standard to produce reliable inference of past environmental conditions.

Thirdly, by studying the lake's living midge fauna, the chance always exists to encounter additional morphotypes not represented in the death assemblages, hence, improving our knowledge on Lake Tanganyika's biodiversity. Indeed, Ablabesmyia type Murusi has now been recorded for the first time in Lake Tanganyika. Similarly, compared to Eggermont \& Verschuren $(2003 a, b)$, the study of Theunissen (1993) revealed an additional five taxa, bringing the total number of Lake Tanganyika's chironomid taxa to 83. Recent work (e.g. Wright \& Cranston 2000; Wright \& Burgin 2007) suggests that the additional collection of pupal exuviae can allow for an even more complete picture of local chironomid diversity.

Finally, examination of the lake's live fauna helps to determine to what extent riverine taxa from the lake's tributary streams are mixed with lacustrine 
death assemblages deposited in bottom sediments. The scarcity of Orthocladiinae in this collection (1 taxon or $6 \%$ of local diversity; two specimens or $1.4 \%$ of total abundance) was surprising, based on Eggermont \& Verschuren's (2003a) findings for Lake Tanganyika, in which 19 Orthocladiinae taxa, or nearly one quarter of total diversity, were recorded. Since most Orthocladiinae do not tolerate low oxygen levels, they are usually found only in cool and fast-running streams in tropical Africa (MacDonald 1956). Several genera are also known to inhabit unstable sandy bottoms that most other taxa avoid (Pinder 1995). Eggermont \& Verschuren (2003b), therefore, hypothesized that the high energy, well-oxygenated littoral zones of Lake Tanganyika simulates these conditions explaining the greater representation of this subfamily in the lake. Indeed, three live Orthocladiinae taxa recorded by Theunissen (1993) were found in the splash zone or at $10 \mathrm{~m}$ water depth, but not in the deeper sediments nor in the tributary Ntahangwa stream. The latter did contain five other Orthocladiinae taxa, but except for Rheocricotopus, none of these have ever been recorded in the lake itself. Eggermont \& Verschuren $(2003 a, b)$ already considered Rheocricotopus to be a truly riverine component, as all three African species are known to inhabit running waters (Harrison 1992). In contrast, the remaining Orthocladiinae genera recorded from the lake, itself, all include one or more species adapted to a lentic habitat. Undoubtedly, limited sampling in the wave-swept, sandy littoral habitats contributed to our results, and further sampling effort in this zone and in rocky shoreline habitats may as yet reveal a greater Orthocladiinae presence. In any case, more live studies are needed to assess the actual lake-dwelling species among this subfamily versus the contribution to lentic death assemblages of head capsules derived from the midge fauna in tributary streams.

\section{CONCLUSIONS}

The fossil data set currently available for Lake Tanganyika comprises a total of 36 surfacesediment samples recovered between 53 and $189 \mathrm{~m}$ water depth from seven deltas areas. This is not enough to develop an internal depthinference model. Although the dataset represents a broad range of depths among a variety of lake bottom substrates, bottom slopes, and oxygen regimes, it also covers the full spectrum of physical disturbance regimes from river sedimentation blurring to some extent the natural, mainly depth-related habitat variation. Moreover, to fully cover all the different habitat types that might have become available during Lake Tanganyika's history of lake-level change, and given the rather high faunal specificity of individual deltas (Eggermont \& Verschuren 2003c), the sampling design should be more comprehensive, covering not only the eastern but also western shoreline habitats.

Quantitatively inferring depth from Lake Tanganyika's fossil chironomid fauna will ultimately require a very extensive, spatially coherent and internally consistent calibration data set, which is not available at this time. Yet, the combined evidence from, and the fairly good correspondence between this and previous studies clearly show that there is a distinct relationship between Lake Tanganyika's chironomid species distribution and depth-related lake bottom characteristics, and that the lake's near- to offshore gradient in chironomid habitat remains imprinted on fossil assemblages. Surface-sediment death assemblages deposited recently at various locations and microhabitats within the lake can, thus, be used as modern reference data for palaeo-depth inference. Moreover, taxonomic resolution of African fossil chironomid studies clearly matches that of live studies, thus, ecological information retrieved from live specimens can immediately feed back into African palaeoenvironmental studies. Together, these findings suggest that Lake Tanganyika's habitat-specific fossil chironomid assemblages can be exploited for within-lake calibration of depth gradients.

\section{ACKNOWLEDGEMENTS}

Fieldwork for this research was conducted in conjunction with the Nyanza Project, a tropical lakes research program at Lake Tanganyika (NSF grant no. ATM0223920 and ATM9619458). Additional funding for D.K. was provided by a Geological Society of America grant, the Wilson Raynor Thompson Memorial Scholarship, the Sulzer Earth Science Scholarship, and a University of Arizona Department of Geosciences fellowship. S.T.H. was funded by the University of Kansas Graduate Research Fund. H.E. is postdoctoral fellow with the Fund for Scientific Research (FWO-Flanders, Belgium). We thank the Tanzanian Fisheries Research Institute for use of their facilities 
and equipment; the University of Dar es Salaam; E.A. Michel, G. Kazumbe, O. K. Davis, C. Gans and B. Graham for invaluable assistance and advice.

\section{REFERENCES}

ALIN, S.R. \& COHEN, A.S. 2003. Lake-level history of Lake Tanganyika, East Africa, for the past 2500 years based on ostracod-inferred water-depth reconstruction. Palaeogeography, Palaeoclimatology, Palaeoecology 199: $31-49$.

ALIN, S.R \& COHEN, A.S. 2004. The live, the dead, and the very dead: taphonomic calibration of the recent record of palaeoecological change in Lake Tanganyika, East Africa. Paleobiology 30: 44-81.

BATTARBEE, R.W. \& FLOWER, R.J. 1984. The inwash of catchment diatoms as a source of error in sedimentbased reconstructions of $\mathrm{pH}$ in an acid lake. Limnology and Oceanography 29: 1325-1329.

BERG, M.B. 1995. Larval food and feeding behavior. In: Armitage, P., Cranston, P. \& Pinder, L.C.V. (Eds) The Chironomidae: The Biology and Ecology of Non-biting Midges. 136-168. Chapman and Hall, London.

BRINKHURST, R.O. 1974. The Benthos of Lakes. MacMillan Press, London.

BROOKS, S.J., LANGDON, P.G. \& HEIRI, O. 2007. The identification and use of Palaearctic Chironomidae larvae in palaeoecology. Quaternary Research Association Technical Guide 10: 1-276.

CHARLES, D.F., DIXIT, S.S., CUMMING, B.F. \& SMOL, J.P. 1991. Variability in diatom and chrysophyte assemblages and inferred $\mathrm{pH}$ : paleolimnological studies of Big Moose Lake, New York, USA. Journal of Paleolimnology 5: 267-284.

CHRISPEELS, A. 1959. Larves de Chironomidae (Diptera Nematocera). Institut royal des Sciences naturelles de Belgique, Exploration hydrobiologique des Lacs Kivu, Edouard et Albert: Résultats scientifiques 3/3: 139-188.

COFFMAN, W.P. \& FERRINGTON, L.C. 1984. Chironomidae. In: Merritt, R.W. \& Cummins, K.W. (Eds) $A n$ Introduction to the Aquatic Insects of North America. 3rd Edition. 635-754. Kendall/Hunt, Dubuque.

COHEN, A.S. 1995. Paleoecological approaches to the conservation biology of benthos in ancient lakes: a case study from Lake Tanganyika. Journal of the North American Benthological Society 14(4): 654-668.

COHEN, A.S. 2000. Linking spatial and temporal changes in the diversity structure of ancient lakes: examples from the ecology and paleoecology of the Tanganyikan ostracods. In: Rossiter, A. \& Kawanabe, H. (Eds). Advances in Ecological Research, Volume 31, Ancient Lakes: Biodiversity, Ecology and Evolution. 521-537. Academic Press, San Diego.

COHEN, A.S., BILLS, R., COCQUYT, C.Z. \& CALJON, A.J. 1993a. The impact of sediment pollution on biodiversity in Lake Tanganyika. Conservation Biology 7: 667-677.

COHEN, A.S., OREGHAN, M.J. \& SCHOLZ, C.A. 1993b. Estimating the age of formation of lakes: an example from Lake Tanganyika, East African Rift system. Geology 21: 511-514.

COHEN, A.S. 2000. Linking spatial and temporal change in the diversity structure of ancient lakes: examples from the ecology and palaeoecology of the Tanganyikan ostracods. Advances in Ecological Research 31: 521-537.

CONTRERAS-LICHTENBERG, R. 1986. Revision der in der Westpaläarktis verbreiteten Arten des genus Dicrotendipes Kieffer, 1913 (Diptera, Nematocera, Chironomidae). Annalen des Naturhistorischen Museums in Wien 88/89B: 663-726.

CONTRERAS-LICHTENBERG, R. 1988. Zur Kenntnis der Jugendstadien von Dicrotendipes septemmaculatus (Becker, 1908) (Diptera, Nematocera, Chironomidae). Zeitschrift der Wiener Entomologischen Gesellschaft 40: 45-48.

COULTER, G.W. 1991. Lake Tanganyika and its Life. 354. Oxford University Press, New York.

CRANSTON, P.S. 1995. Introduction to the Chironomidae. In: Armitage, P., Cranston, P.S. \& Pinder, L.C.V. (Eds) The Chironomidae: the Biology and Ecology of Non-biting Midges. 1-7. Chapman \& Hall, New York.

CRANSTON, P.S. \& JUDD, D.D. 1989. Diptera: Fam. Chironomidae of the Arabian Peninsula. In: Krupp, F. (Ed.) Fauna of Saudi Arabia 10: 236-289.

DEGENS, E.T., VON HERZEN, R.P. \& WONG, H.K. 1971. Lake Tanganyika: water chemistry, sediments, geological structure. Naturwissenschaften 58: 229-241.

DEJOUX, C. 1968. Le lac Tchad et les chironomids de sa partie. Annales Zoologici Fennici 5: 27-32.

DEJOUX, C. 1971. Contribution á l'étude des premiers états des chironomides du Tchad (Insectes, Diptères) (5e note). Description de Chironomus (Cryptochironomus) deribae et Polypedilum (Polypedilum) fuscipienne. Cahiers ORSTOM, série Hydrobiologie 5: 87-100.

DEJOUX, C. 1973. Contribution á l'étude des premiers états des chironomides du Tchad (Insectes, Diptères) (6e note). Description de Tanytarsus (Rheotanytarsus) ceratophylli n. sp. Cahiers ORSTOM, série Hydrobiologie 6: $65-75$.

EGGERMONT, H. 1999. The influence of soil erosion in Burundi and western Tanzania on the benthic invertebrate biodiversity in Lake Tanganyika, East Africa [in Dutch]. M.Sc. thesis, Ghent University, Ghent, Belgium.

EGGERMONT, H. 2004. Fossil Chironomidae (Insecta: Diptera) as quantitative indicators for past salinity variation in African lakes: taxonomy, inference models, and assessment of models in space and time. Ph.D. dissertation, Ghent University, Ghent, Belgium.

EGGERMONT, H. \& VERSCHUREN, D. 2003a. Subfossil Chironomidae from Lake Tanganyika, East Africa 1. Tanypodinae and Orthocladiinae. Journal of Paleolimnology 29: 31-48.

EGGERMONT, H. \& VERSCHUREN, D. 2003b. Subfossil Chironomidae from Lake Tanganyika, East Africa 2. (Chironomini and Tanytarsini). Journal of Paleolimnology 29: 423-457.

EGGERMONT, H. \& VERSCHUREN, D. 2003c. Impact of soil erosion in tributary drainages on the benthic invertebrate fauna of Lake Tanganyika, East Africa. Biological Conservation 113: 99-109.

EGGERMONT, H. \& VERSCHUREN, D. 2004a. Subfossil Chironomidae from East Africa. 1. Tanypodinae and Orthocladiinae. Journal of Paleolimnology 32: 383-412. EGGERMONT, H. \& VERSCHUREN, D. 2004b. Subfossil 
Chironomidae from East Africa. 2. Chironominae (Chironomini and Tanytarsini). Journal of Paleolimnology 32: 413-455.

EGGERMONT, H., VERSCHUREN, D. \& DUMONT, H.J. 2005. Taxonomic diversity and biogeography of Chironomidae (Insecta: Diptera) in lakes of tropical West Africa using subfossil remains extracted from surface sediments. Journal of Biogeography 32: 10631083.

EGGERMONT, H. \& VERSCHUREN, D. 2007. Taxonomy and diversity of Afroalpine Chironomidae (Insecta: Diptera) on Mount Kenya and the Ruwenzori Mountains, East Africa. Journal of Biogeography 34: 69-89.

EGGERMONT, H., HEIRI, O. \& VERSCHUREN, D. 2006. Subfossil Chironomidae (Insecta: Diptera) as quantitative indicators for past salinity variation in African lakes. Quaternary Science Reviews 25: 1966-1994.

EKREM, T. 1999. Cladotanytarsus bukavus (Lehmann 1979) comb. n. and C. congolensis (Lehmann 1979) comb. n. from Central Africa (Diptera: Chironomidae). Annals de Limnologie 35(3): 185-191.

EPLER, J.H. 1988. Biosystematics of the genus Dicrotendipes Kieffer, 1913 (Diptera: Chironomidae: Chironominae) of the world. Memoirs of the American Entomological Society 36: 1-214.

EPLER, J.H. 1995. Identification Manual for the Larval Chironomidae (Diptera) of Florida. Revised Edition. Systematic Entomologist, Crawfordville.

EPLER, J.H. 2001. Identification Manual for the Larval Chironomidae (Diptera) of North and South Carolina. Systematic Entomologist, Crawfordville.

FREEMAN, P. 1956. A study of the Chironomidae (Diptera) of Africa South of the Sahara, Part 2. Bulletin of the British Museum (Natural History) Entomology 5: 285-366.

FREEMAN, P. 1957. A study of the Chironomidae (Diptera) of Africa South of the Sahara, Part 3. Bulletin of the British Museum (Natural History) Entomology 5: 323-426.

FREEMAN, P. \& CRANSTON, P.S. 1980. Family Chironomidae. In: Crosskey, R.W. (Ed.) Catalogue of the Diptera of the Afrotropical Region. 175-202. British Museum (Natural History), London.

FREY, D.G. 1988. Littoral and offshore communities of diatoms, cladocerans and dipterous larvae, and their interpretation in paleolimnology. Journal of Paleolimnology 1: 179-191.

HARRISON, A.D. 1987. Chironomidae of five central Ethiopian Rift Valley lakes. Entomologica Scandinavica Supplement 29: 39-43.

HARRISON, A. 1991. Chironomidae from Ethiopia. Part 1. Tanypodinae (Insecta Diptera). Spixiana 14: 45-69.

HARRISON, A.D. 1992. Chironomidae from Ethiopia. Part 2. Orthocladiinae with two new species and a key to Thienemanniella Kieffer (Insecta: Diptera). Spixiana 15: 149-195.

HARRISON, A.D. 1993. Dicrotendipes pilosimanus Kieffer: a description of all life stages, and features which distinguish it from Dicrotendipes septemmaculatus Becker (Insecta, Diptera: Chironomidae). Annals of the Cape Provincial Museums (Natural History) 18: 357-370.

HARRISON, A.D. 1996. Chironomidae from Ethiopia. Part 3. Chironomini, with description of a new species (Insecta, Diptera). Spixiana 19: 43-87.
HARRISON, A.D. 2000. The non-biting midges (Diptera: Chironomidae) of South Africa. Online: http://www. ru.ac.za/academic/departments/zooento/Martin/ chironomidae.html

HEIRI, O., LOTTER, A.F. \& LEMCKE, G. 2001. Loss on ignition as a method for estimating organic and carbonate content in sediments: reproducibility and comparability of results. Journal of Paleolimnology 25: 101-110.

HORI, M., GASHAGAZA, M.M., NSHOMBO, M. \& KAWANABE 1993. Littoral fish communities in Lake Tanganyika: irreplaceable diversity supported by intricate interactions among species. Conservation Biology 7: 657-666.

KUGLER, J. 1971. The development stages of Leptochironomus stilifer (Diptera: Chironomidae) and the characters of the genus Leptochironomus. The Canadian Entomologist 103: 341-346.

KIBRET, T. \& HARRISON, A.D. 1989. The benthic and weedbed fauna faunas of Lake Awassa (Rift Valley, Ethiopia). Hydrobiologia 174: 1-15.

LEHMANN, J. 1979. Chironomidae (Diptera) aus Fließgewässern Zentralafrikas (Systematik, Ökologie, Verbreitung und Produktionsbiologie), Teil I. KivuGebiet, Ostzaire. Spixiana Supplement 3: 1-144.

LEHMANN, J. 1981. Chironomidae (Diptera) aus Fließgewässern Zentralafrikas, Teil II. Die Region um Kisangani, Zentralzaire. Spixiana Supplement 5: 1-85.

MANCA, M., NOCENTINI, A.M., BELIS, C.A., COMOLI, P. \& CORBELLA, L. 1996. Invertebrate fossil remans as indicators of Late Quaternary environmental change in Latium Lakes (L. Albano and L. Nemi). Memorie dell'Istituto Italiano di Idrobiologia 55: 149-176.

MACDONALD, W.W. 1956. Observations on the biology of chaoborids and chironomids in Lake Victoria and on the feeding habits of the 'elephant-snout fish' (Mormyrus kannune Forsk.). Journal of Animal Ecology 25: 36-53.

McGLUE, M.M., LEZZAR, K.E., COHEN, A.S., RUSSELL, J.M., TIERCELIN, J-J., FELTON, E.E., MBEDE, E. \& NKOTAGU, H.H. 2008. Seismic records of late Pleistocene aridity in Lake Tanganyika, tropical Africa. Journal of Paleolimnology: doi 10.1007/s10933007-9187.

McKEE, B.A., COHEN, A.S., DETTMAN, D.L., PALACIOS-FEST, M.R., ALIN, S.R. \& NTUNGUMBURANYE, G. 2005. Paleolimnological investigations of anthropogenic environmental change in Lake Tanganyika: II. Geochronologies and mass sedimentation rates based on ${ }^{14} \mathrm{C}$ and ${ }^{210} \mathrm{~Pb}$ data. Journal of Paleolimnology 34: 19-29.

McKINNEY, M.L. 1991. Completeness of the fossil record: an overview. In: Donovan, S.K. (Ed.) The Processes of Fossilization. 66-83. Columbia University Press, New York.

McLACHLAN, A.J. 1969. Notes on some larval and pupal chironomids (Diptera) from Lake Kariba, Rhodesia. Journal of Natural History 3: 261-293.

MOLLER-PILLOT, H.K.M. 1984a. De Larven der Nederlandse Chironomidae (Diptera) - Inleiding, Tanypodinae en Chironominae. Nederlandse Faunistische Mededelingen 1a: 1-277.

MOLLER-PILLOT, H.K.M. 1984b. De Larven der 
Nederlandse Chironomidae (Diptera) - Orthocladiinae sensu lato. Nederlandse Faunistische Mededelingen 1: 1-175.

NICHOLSON, S.E. 1999. Historical and modern fluctuations of lakes Tanganyika and Rukwa and their relationship to rainfall variability. Climatic Change 41: 53-71.

OLIVER, D.R. \& ROUSSEL, M.E. 1983. The Genera of Larval Midges of Canada (Diptera: Chironomidae). Research Branch, Agriculture Canada, Ottawa. Publication No. 1746 .

OYEWO, E.A. \& SÆTHER, O.A. 1998. Revision of Afrotropical Polypedilum Kieffer subgen. Uresipedilum Sasa et Kikuchi, 1995 (Diptera: Chironomidae), with a review of the subgenus. Annals de Limnologie 34(3): 315-362.

PARK, L.E., COHEN, A.S. \& MARTENS, K. 2000. Ecology and specialization of the ostracod clade (Gomphocythere) in a tropical lake ecosystem, Lake Tanganyika, East Africa. Verhandlungen Internationale Vereinigung für Theoretische und Angewandte Limnologie 27: 2665-2669.

PETR, T. 1972. Benthic fauna of a tropical man-made lake (Volta Lake, Ghana 1965-1968). Archiv für Hydrobiologie 70: 484-533.

PINDER, L.C.V. 1995. The habitats of chironomid larvae. In: Armitage, P., Cranston, P.S. \& Pinder, L.C.V. (Eds) The Chironomidae: the Biology and Ecology of Non-biting Midges. 108-135. Chapman and Hall, London.

PINDER, L.C.V. \& REISS, F. 1983. The larvae of Chironominae (Diptera: Chironomidae) of the Holarctic region - Keys and diagnoses. Entomologica Scandinavica Supplement 19: 293-435.

PLISNIER, P.D., CHITAMWEBWA, D. MWAPE, L., TSHIBANGU, K., LANGENBERG, V. \& COENEN, E. 1999. Limnological annual cycle inferred from physical-chemical fluctuations at three stations of Lake Tanganyika. Hydrobiologia 407: 45-58.

PRIMER-E LTD 2001. Primer version 5.2.4. Roborough, Plymouth, U.K.

ROSENBERG, D.M. \& RESH, V.H. 1993. Freshwater Biomonitoring and Benthic Macroinvertebrates. Chapman Hall, New York.

RIERADEVALL, M. \& BROOKS, S.J. 2001. An identification guide to sub-fossil Tanypodinae (Insecta: Diptera: Chironomidae) based on cephalic setation: Journal of Paleolimnology 25: 81-99.

RUMES, B., EGGERMONT, H. \& VERSCHUREN, D. 2005. Representation of aquatic invertebrate communities in subfossil death assemblages along a salinity gradient of western Uganda crater lakes. Hydrobiologia 542: 297-314.

SÆTHER, O.A. 1980. Glossary of chironomid morphology terminology (Diptera: Chironomidae). Entomologica Scandinavica Supplement 14: 1-51.

SÆTHER, O.A. \& SUNDAL, A. 1998. Cerobregma, a new subgenus of Polypedilum Kieffer, with a tentative phylogeny of subgenera and species groups within Polypedilum (Diptera: Chironomidae). Journal of the Kansas Entomological Society 71(3): 315-382.

SHANNON, C.E. \& WIENER, W. 1963. The Mathematical
Theory of Communication. University of Illinois Press, Urbana/Chicago.

THEUNISSEN, B. 1993. Chironomid larvae (Diptera, Chironomidae) in the northern bay of Lake Tanganyika and the Ntahangwa river (Burundi) (in Dutch). M.Sc. thesis, University of Leuven, Leuven, Belgium.

TOKESHI, M. 1995. Species interactions and community structure. In: Armitage, P., Cranston, P.S. \& Pinder, L.C.V. (Eds) The Chironomidae: The Biology and Ecology of Non-biting Midges. 297-335. Chapman and Hall, London.

TUDORANCEA, C., BAXTER, R.M. \& FERNANDO, C.H. 1989. A comparative limnological study of zoobenthic communities in lakes of the Ethiopian Rift Valley. Archiv für Hydrobiologie Supplement 83: 121-174.

TUDORANCEA, C. \& HARRISON, A.D. 1988. The benthic communities of the saline Lakes Abijata and Shala (Ethiopia). Hydrobiologia 158: 117-123.

VERSCHUREN, D. 1997. Taxonomy and ecology of sub-fossil Chironomidae (Insecta: Diptera) from Rift Valley lakes in central Kenya. Archiv für Hydrobiologie Beihefte 107: 467-512.

VERSCHUREN, D., TIBBY, J., SABBE, K. \& ROBERTS, C.N. 2000. Effects of lake level, salinity and substrate on the invertebrate community of a fluctuating tropical lake. Ecology 81: 164-182.

VERSCHUREN, D., CUMMING, B.F. \& LAIRD, K.R. 2004. Quantitative reconstruction of past salinity variations in African lakes using fossil midges (Diptera: Chironomidae): assessment of inference models in space and time: Canadian Journal of Fisheries and Aquatic Sciences 61: 986-998.

VERSCHUREN, D. \& EGGERMONT, H. 2006, Quaternary paleoecology of aquatic Diptera in tropical and southern Hemisphere regions, with special reference to the Chironomidae. Quaternary Science Reviews 25: 1926-1947.

WALKER, I.R. 2001. Midges: Chironomidae and related Diptera. In: Smol, J.P, Birks, H.J.B \& Last W.M. (Eds) Tracking Environmental Change Using Lake Sediments. Vol. 4, Zoological Indicators. Kluwer Academic Publishers, Dordrecht.

WALKER, I.R. 2007. Chironomid overview. In: Elias, S. (Ed.) Encyclopedia of Quaternary Sciences Vol. 1. 360-366. Elsevier, Oxford.

WENTWORTH, C.K. 1922. A scale of grade and class terms for clastic sediments. Journal of Geology 30: 377-392.

WIEDERHOLM, T. 1983. Chironomidae of the Holarctic region. Keys and diagnoses. Part. 1. Larvae. Entomologica scandinavica Supplement 19: 1-457.

WRIGHT, I.A. \& CRANSTON, P.S. 2000. Are Australian lakes different? Chironomid and chaoborid exuviae from Lake McKenzie, a costal temperate dune lake. Verhandlung der Internationale Vereinigung für Theoretische und Angewandte Limnologie 27: 303-308.

WRIGHT, I.A. \& BURGIN, S. 2007. Species richness and distribution of eastern Australian lake chironomids and chaoborids. Freshwater Biolology 52: 2354-2368. 